\title{
Inhibition of Bruton's tyrosine kinase activity attenuates trauma-induced multiple organ dysfunction in rats
}

Nikita M Patel ${ }^{1 *}$, MSci, Filipe RMB Oliveira ${ }^{2}$, MSc, Hanna Pillmann Ramos², Eleonora Aimaretti $^{3}$, MSc, Gustavo Ferreira Alves ${ }^{4}$, MSc, Sina M Coldewey ${ }^{5}, \mathrm{MD} \mathrm{PhD}$, Massimo Collino ${ }^{4}, \mathrm{PhD}$, Regina Sordi², PhD, Christoph Thiemermann ${ }^{1}, \mathrm{MD} \mathrm{PhD}$

${ }^{1}$ William Harvey Research Institute, Barts and The London School of Medicine and Dentistry, Queen Mary University of London, London, United Kingdom

${ }^{2}$ Department of Pharmacology, Universidade Federal de Santa Catarina, SC, Brazil

${ }^{3}$ Department of Clinical and Biological Sciences, University of Turin, Turin, Italy

${ }^{4}$ Department of Neurosciences "Rita Levi Montalcini”, University of Turin, Turin, Italy

${ }^{5}$ Department of Anesthesiology and Intensive Care Medicine, Jena University Hospital, Jena, Germany

\section{*Addresses for correspondence and requests for reprints:}

Nikita Mayur Patel, MSci

William Harvey Research Institute,

Barts and The London School of Medicine and Dentistry,

Queen Mary University of London,

London, United Kingdom

n.m.patel@qmul.ac.uk

Phone: +44 (0) 7852106575

Running title: BTKi attenuate trauma-induced MODS 
Type of study: Original study

Sources of support: NMP was funded by the William Harvey Research Foundation, FRMBO and HPR were funded by National Council for Scientific and Technological Development (CNPq) fellowship. National Council for Scientific and Technological Development to RS (CNPq, Brazil, Grant 409018/2018-0).

\section{AUTHOR CONTRIBUTIONS}

Conception and design: NMP, RS, and CT;

Acquisition of data: NMP, FRMBO, HPR and RS;

Analysis and interpretation of data: NMP, FRMBO, HPR, EA, GFA, SC, MC, RS, CT

Drafting the manuscript for important intellectual content: NMP and CT

All authors reviewed and approved the manuscript.

\section{MINI-ABSTRACT}

This study evaluated the role of Bruton's tyrosine kinase (BTK) in trauma/hemorrhage. Patients with trauma had elevated gene expression of BTK. The BTK inhibitors acalabrutinib (irreversible) and fenebrutinib (reversible) attenuated the trauma-induced multiple organ dysfunction in rats with hemorrhagic shock, indicating that BTK could be a potential therapeutic target. 


\section{ABSTRACT}

Objective: The aim of this study was to investigate (a) the potential of the Bruton's tyrosine kinase (BTK) inhibitors (BTKi) acalabrutinib and fenebrutinib to reduce multiple organ dysfunction syndrome (MODS) in acute and chronic hemorrhagic shock (HS) rat models and (b) whether treatment with either acalabrutinib or fenebrutinib attenuates BTK, NF- $\mathrm{B}$ and NLRP3 activation in HS.

Background: The MODS caused by an excessive systemic inflammatory response following trauma is associated with a high morbidity and mortality. The protein BTK is known to play a role in the activation of the NLRP3 inflammasome, which is a key component of the innate inflammatory response. However, its role in trauma-hemorrhage is unknown.

Methods: Acute and chronic HS rat models were performed to determine the influence of acalabrutinib or fenebrutinib on MODS. The activation of BTK, NF-אB and NLRP3 pathways were analyzed by western blot in the kidney.

Results: We demonstrated that (a) HS caused organ injury and/or dysfunction and hypotension (post resuscitation) in rats, while (b) treatment of HS-rats with either acalabrutinib or fenebrutinib attenuated the organ injury and dysfunction in acute and chronic HS models and (c) reduced the activation of BTK, NF-אB and NLRP3 pathways in the kidney.

Conclusion: Our results point to a role of BTK in the pathophysiology of organ injury and dysfunction caused by trauma/hemorrhage and indicate that BTK inhibitors may be repurposed as a potential therapeutic approach for MODS after trauma and/or hemorrhage.

KEYWORDS: acalabrutinib; Bruton's tyrosine kinase; fenebrutinib; hemorrhagic shock; ischemia-reperfusion; multiple organ dysfunction syndrome; trauma 


\section{ABBREVIATIONS}

ALT alanine aminotransferase

AST aspartate aminotransferase

BTK Bruton's tyrosine kinase

BTKi Bruton's tyrosine kinase inhibitors

CK creatine kinase

DAMP damage-associated molecular pattern

FDA Food and Drug Administration

HR heart rate

HS hemorrhagic shock

$\mathrm{I} / \mathrm{R} \quad$ ischemia-reperfusion

LDH lactate dehydrogenase

MAP mean arterial pressure

MODS multiple organ dysfunction syndrome

MPO myeloperoxidase 


\section{INTRODUCTION}

Trauma is one of the leading causes of death and disability in those aged under 44 and exceeds the number of deaths caused by HIV, tuberculosis and malaria combined ${ }^{1}$. Globally, there are approximately 6 million trauma-related deaths each year. In contrast to most other diseases, instances of trauma and the accompanying mortality rates are rising. Trauma-associated hemorrhage accounts for almost $40 \%$ of all trauma mortalities and is frequently considered the biggest cause of preventable deaths in the world ${ }^{2}$. Trauma patients, who survive the initial injury, often develop multiple organ dysfunction (MODS) at a later stage ${ }^{3}$. Whilst the underlying mechanisms contributing to MODS have not been fully elucidated, it is thought that a) an excessive systemic inflammatory response secondary to the release of damage-associated molecular patterns (DAMPs) from extensive tissue damage and $b$ ) ischemia-reperfusion (I/R) injury play an important role ${ }^{4}$. At present, there are no specific pharmacological interventions used clinically to prevent the onset of MODS associated with HS.

Bruton's tyrosine kinase (BTK) is a cytoplasmic, non-receptor protein tyrosine kinase belonging to the Tec family of kinases and was first discovered in $\mathrm{X}$-linked agammaglobulinemia ${ }^{5}$. All cells of hematopoietic origin except plasma cells, natural killer cells and T-lymphocytes express BTK ${ }^{6}$. Whilst BTK was initially known for its critical role in Blymphocyte development and, thus, adaptive immunity, more recent studies point to a pivotal role for BTK in innate immunity ${ }^{7}$.

It is known that trauma leads to a so-called 'genomic storm' that results in a change in $>80 \%$ of cellular functions and pathways ${ }^{8}$. Specifically, there is an increased expression in genes related to systemic inflammatory and innate immune responses. Of particular interest was the observation that B-lymphocyte receptor signaling was one of the most upregulated pathways. 
We have recently discovered that inhibition of BTK activity with either ibrutinib or acalabrutinib reduces the multiple organ (cardiac, renal, hepatic) injury/dysfunction caused by cecum-ligation and puncture (CLP)-sepsis in the mouse. Moreover, the BTKi used reduced the activation of NF- $\mathrm{BB}$ and the NLRP3 inflammasome as well as the release of many proinflammatory cytokines and chemokines triggered by CLP-sepsis ${ }^{9}$. Most notably, X-Linked immunodeficient mice with inactive BTK function were also protected from sepsis-induced $\operatorname{MODS}^{10}$. Furthermore, prevention of NF- $\kappa \mathrm{B}$ activation reduces the onset of multiple organ injury and improves the survival rate in rodent models of septic shock ${ }^{11}$, whilst pharmacological blockade of NF- $\kappa \mathrm{B}$ activation using inhibitors of I $\mathrm{B}$ kinase reduced the MODS caused by CLP ${ }^{12}$ and $\mathrm{HS}^{13}$.

Driven by the COVID-19 pandemic, there has been a significant focus on interventions (repurposing) that dampen the cytokine storm and pulmonary injury linked to severe acute respiratory syndrome coronavirus 2 (SARS-CoV-2). Most notably, there is a positive correlation between disease severity and BTK activity following SARS-CoV-2 infection ${ }^{14-16}$. Thus, BTKi appear to reduce systemic inflammation and ongoing clinical trials will assess the potential impact of this repurposing strategy on outcome in patients with COVID-19 (ClinicalTrials.gov Identifier: NCT04382586, NCT04665115, NCT04439006, NCT04375397, NCT04528667 and NCT04440007).

BTKi are commonly used in patients for the treatment of B-lymphocyte malignancies such as chronic lymphocytic leukemia and mantle cell lymphoma. However, they have also received approval by the Food and Drug Administration (FDA) for use in patients with marginal zone lymphoma, small lymphocytic lymphoma, Waldenström's macroglobulinemia and chronic 
bioRxiv preprint doi: https://doi.org/10.1101/2021.09.23.460775; this version posted September $24,2021$. The copyright holder for this preprint (which was not certified by peer review) is the author/funder, who has granted bioRxiv a license to display the preprint in perpetuity. It is made available under aCC-BY-NC-ND 4.0 International license.

graft versus host disease ${ }^{17}$. Given the evident protective effects of BTKi administration in sepsis and COVID-19, both of which display an excessive systemic inflammatory response, we wished to explore the potential of repurposing BTKi in trauma-hemorrhage.

There is limited information about the role of BTK in trauma ${ }^{18}$. Using the gene expression data in whole blood leukocytes of trauma patients ${ }^{8}$, we reanalyzed the expression of BTK. Having found a significant increase in BTK expression in patients with trauma, we then used a reverse translational approach to investigate the effect of the commercially available, irreversible BTKi acalabrutinib and the novel, reversible BTKi fenebrutinib on the organ injury/dysfunction in two rat models of HS. Having shown that both BTKi largely abolished the organ injury/dysfunction associated with hemorrhagic shock, we then investigated whether or not modulation of the BTK activity may affect the activation of selective inflammatory pathways, which are known to be involved in trauma/hemorrhage, specifically both the NF- $\mathrm{B}$ and the NLRP3 inflammasome cascades. 


\section{METHODS}

BTK gene expression in human whole blood

Original data was obtained under Gene Expression Omnibus (GEO) accession GSE36809, published by Xiao and colleagues ${ }^{8}$. RNA was extracted from whole blood leukocytes of severe blunt trauma patients $(n=167)$ over the course of 28 days and healthy controls $(n=37)$ and hybridized onto an HU133 Plus 2.0 GeneChip (Affymetrix) according to the manufacturer's recommendations. The dataset was reanalyzed for BTK gene expression in these two groups.

\section{Use of Experimental Animals - Ethical Statement}

For the acute HS model, all animal procedures were approved by the Animal Welfare Ethics Review Board (AWERB) of Queen Mary University of London and by the Home Office (License number PC5F29685). For the chronic HS model, all animal procedures were approved by the Universidade Federal de Santa Catarina Institutional Committee for Animal Use in Research (License number 7396250219) and are in accordance with the Brazilian Government Guidelines for Animal Use in Research (CONCEA). All in vivo experiments are reported in accordance to ARRIVE guidelines.

\section{Experimental Design}

Male Wistar rats (for acute model: Charles River Laboratories Ltd., UK; for chronic model: Universidade Federal de Santa Catarina, Brazil) weighing 250-350 g were kept under standard laboratory conditions ( $\left.12 \mathrm{~h} \mathrm{light/dark} \mathrm{cycle} \mathrm{with} \mathrm{the} \mathrm{temperature} \mathrm{maintained} \mathrm{at} 19-22{ }^{\circ} \mathrm{C}\right)$ and received a chow diet and water ad libitum. All animals were allowed to acclimatize to laboratory conditions for at least one week before undergoing any experimentation. Acalabrutinib (3 mg/kg; Insight Biotechnology, UK) and fenebrutinib (3 mg/kg; Insight 
Biotechnology, UK) were separately diluted in $5 \%$ DMSO + $95 \%$ Ringer's Lactate (vehicle) and rats were treated (i.v. in acute and i.p. in chronic model) upon resuscitation.

\section{Acute Hemorrhagic Shock Model}

The acute hemorrhagic shock model was performed as previously described ${ }^{19-21}$. Briefly, fiftyfour rats were anesthetized with sodium thiopentone $(120 \mathrm{mg} / \mathrm{kg}$ i.p. initially and $10 \mathrm{mg} / \mathrm{kg}$ i.v. for maintenance as needed) and randomized into six groups: Sham + vehicle $(n=9)$; Sham + acalabrutinib (3 mg/kg; $\mathrm{n}=8)$, Sham + fenebrutinib (3 mg/kg; $\mathrm{n}=8), \mathrm{HS}+$ vehicle $(\mathrm{n}=9) ; \mathrm{HS}$ + acalabrutinib (3 mg/kg; $\mathrm{n}=10)$; HS + fenebrutinib (3 mg/kg; $\mathrm{n}=10)$. Blood was withdrawn to achieve a fall in mean arterial pressure (MAP) to $35 \pm 5 \mathrm{mmHg}$, which was maintained for $90 \mathrm{~min}$. At $90 \mathrm{~min}$ after initiation of hemorrhage (or when $25 \%$ of the shed blood had to be reinjected to sustain MAP, resuscitation was performed with the shed blood over a period of $5 \mathrm{~min}$. An infusion of Ringer's lactate $(1.5 \mathrm{~mL} / \mathrm{kg} / \mathrm{h})$ was started as fluid replacement $1 \mathrm{~h}$ after resuscitation and was maintained throughout the experiment for a total of $3 \mathrm{~h}$. At $4 \mathrm{~h}$ postresuscitation, blood was collected for the measurement of biomarkers of organ injury/dysfunction (MRC Harwell Institute, Oxfordshire, UK). Sham-operated rats were used as control and underwent identical surgical procedures, but without hemorrhage or resuscitation. Detailed description of the acute hemorrhagic shock model and sample collection can be found in the supplemental section (Supplemental Figure 1A).

\section{Chronic Hemorrhagic Shock Model}

Thirty-eight rats were administered analgesia with tramadol (10 mg/kg i.p.) $15 \mathrm{~min}$ prior to anesthesia induction with ketamine and xylazine $(100 \mathrm{mg} / \mathrm{kg}$ and $10 \mathrm{mg} / \mathrm{kg}$ i.m. respectively) and randomized into four groups: Sham + vehicle $(\mathrm{n}=9)$; Sham + acalabrutinib $(3 \mathrm{mg} / \mathrm{kg} ; \mathrm{n}=$ $10)$; HS + vehicle $(\mathrm{n}=10)$; HS + acalabrutinib $(3 \mathrm{mg} / \mathrm{kg} ; \mathrm{n}=9)$. Blood was withdrawn to 
achieve a fall in MAP to $40 \pm 2 \mathrm{mmHg}$, which was maintained for $90 \mathrm{~min}$. At $90 \mathrm{~min}$ after initiation of hemorrhage (or when $25 \%$ of the shed blood had to be reinjected to sustain MAP), resuscitation was performed with the shed blood over a period of $5 \mathrm{mins}$ plus $1.5 \mathrm{~mL} / \mathrm{kg}$ Ringer's lactate. At 24 h post-resuscitation, blood was collected for the measurement of organ injury parameters (Hospital Universitário Professor Polydoro Ernani de São Thiago, Brazil). Sham-operated rats were used as control and underwent identical surgical procedures, but without hemorrhage or resuscitation. Detailed description can be found in the supplemental section (Supplemental Figure 1B).

\section{Western Blot Analysis}

Semi-quantitative immunoblot analysis was carried out in kidney tissue samples as previously described $^{22}$. The following antibodies were used: rabbit anti-total BTK, rabbit anti-NF-kB, rabbit anti-total IKK $\alpha / \beta$, rabbit anti-Ser ${ }^{176 / 180} \mathrm{IKK} \alpha / \beta$, mouse anti-Ser ${ }^{32 / 36} \mathrm{I} \kappa \mathrm{B} \alpha$, mouse antitotal I $\mathrm{B} \alpha$, (from Cell Signaling), rabbit anti-Tyr ${ }^{223}$-BTK, rabbit anti-NLRP3 inflammasome (from Abcam) and mouse anti-caspase 1 (p20) (from Adipogen). Detailed description of the method can be found in the supplemental section.

\section{Quantification of myeloperoxidase activity}

Lung and liver tissue samples from the chronic HS model were homogenized in liquid nitrogen with a pestle and mortar. The homogenate was then centrifuged at $13,000 \times \mathrm{g}$ at $4{ }^{\circ} \mathrm{C}$ for 10 min and the supernatant was assayed for myeloperoxidase (MPO) activity by measuring the $\mathrm{H}_{2} \mathrm{O}_{2}$-dependent oxidation of 3,3,5,5-tetramethylbenzidine (TMB). MPO activity was determined colorimetrically using an ultra-microplate reader (EL 808, BioTek Instruments, INC, USA) set to measure absorbance at $650 \mathrm{~nm}$. Total protein content in the homogenate was estimated using the BCA assay (Thermo Fisher Scientific, Rockford, IL), according to the 
bioRxiv preprint doi: https://doi.org/10.1101/2021.09.23.460775; this version posted September $24,2021$. The copyright holder for this preprint (which was not certified by peer review) is the author/funder, who has granted bioRxiv a license to display the preprint in perpetuity. It is made available under aCC-BY-NC-ND 4.0 International license.

manufacturer's instructions. MPO activity was expressed as optical density at $650 \mathrm{~nm}$ per mg of protein.

\section{Statistical Analysis}

All data in text and figures are expressed as mean \pm SEM of $n$ observations, where $n$ represents the number of animals/experiments/subjects studied. Measurements obtained from the patient groups and sham, control, acalabrutinib and fenebrutinib treated animal groups were analyzed by one-way ANOVA followed by a Bonferroni's post-hoc test on GraphPad Prism 8.0 (GraphPad Software, Inc., La Jolla, CA, USA). The distribution of the data was verified by Shapiro-Wilk normality test, and the homogeneity of variances by Bartlett test. When necessary, values were transformed into logarithmic values to achieve normality and homogeneity of variances. Differences were considered to be statistically significant when $\mathrm{p}<0.05$. 


\section{RESULTS}

BTK gene expression is elevated in trauma patients

Xiao and colleagues ${ }^{8}$ isolated whole blood leukocytes, extracted the total cellular RNA and performed genome-wide expression analysis by array from severe blunt trauma patient blood samples collected within $12 \mathrm{~h}$ and on Days 1, 4, 7, 14, 21 and 28 post-injury. Genome-wide expression in white blood cells from trauma patients was compared against matched healthy controls. Dataset is available under Gene Expression Omnibus (GEO) accession GSE36809. We reanalyzed this dataset for BTK expression in these groups. When compared to healthy controls, BTK expression was significantly elevated at all time points except $12 \mathrm{~h}(\mathrm{p}<0.05$; Figure 1). An initial peak was noted at Day 1 followed by a gradual decrease, however, BTK expression remained elevated at Day 28.

\section{Treatment with BTKi improves HS-induced circulatory failure in an acute HS model}

To investigate the effects of the BTK inhibitors (BTKi) acalabrutinib and fenebrutinib on circulatory failure, MAP was measured from the completion of surgery to the termination of the experiment. Baseline MAP values were similar amongst all six groups. Rats subjected to HS demonstrated a decline in MAP which was ameliorated by resuscitation, but MAP remained lower than that of sham-operated rats during resuscitation (at the equivalent time points, Figure 2A). When compared to sham-operated rats, HS-rats treated with vehicle exhibited a more pronounced decrease in MAP over time post resuscitation. The MAP of HS-rats treated with either acalabrutinib or fenebrutinib was significantly higher than that of HS-rats treated with vehicle at the end of the resuscitation period $(\mathrm{p}<0.05$; Figure $2 \mathrm{~B})$. No significant differences were observed between HS-rats treated with either acalabrutinib or fenebrutinib $(p>0.05$; Figure 2A). Administration of acalabrutinib or fenebrutinib to sham-operated rats had no significant effect on MAP ( $\mathrm{p}>0.05$; Figure 2A). 


\section{Treatment with BTKi attenuates HS-induced organ damage in an acute HS model}

Here we explored whether pharmacological intervention with the BTKi acalabrutinib and fenebrutinib attenuates the MODS associated with HS in rats. When compared to shamoperated rats, rats subjected to HS and treated with vehicle displayed increases in serum urea $(p<0.05$; Figure $3 A)$ and creatinine $(p<0.05$; Figure $3 B)$; indicating the development of renal dysfunction. When compared to sham-operated rats, vehicle treated HS-rats exhibited significant increases in ALT ( $p<0.05$; Figure 3C) and AST $(p<0.05$; Figure 3D) indicating the development of hepatic injury, while the increases in $\mathrm{CK}(\mathrm{p}<0.05$; Figure $3 \mathrm{E})$ and amylase $(\mathrm{p}<0.05$; not shown) denote neuromuscular and pancreatic injury, respectively. The significant increase in LDH $(p<0.05$; Figure 3F) in HS-rats treated with vehicle confirms that tissue injury had occurred. Treatment of HS-rats with either acalabrutinib or fenebrutinib significantly attenuated the renal dysfunction, hepatic injury, neuromuscular injury and general tissue damage caused by HS as shown by the reduction in serum parameter values (all $\mathrm{p}<0.05$; Figures 3A-F). Treatment with either BTKi had no significant effect on pancreatic injury ( $p>0.05$; not shown). No significant differences were observed between HS-rats treated with either acalabrutinib or fenebrutinib ( $\mathrm{p}>0.05$; Figure 3$)$. Administration of either BTKi to shamoperated rats had no significant effect on any of the parameters measured ( $p>0.05$; Figure 3 ).

\section{Treatment with BTKi abolishes renal BTK activation in an acute HS model}

Using western blot analysis, we examined whether HS leads to the activation of BTK in the kidney; given that treatment with either BTKi significantly attenuated HS-associated renal dysfunction. The activation of BTK and subsequent BTK-associated signaling pathways consists of the phosphorylation of BTK at $\mathrm{Tyr}^{223}$ as the initial stage of the BTK-signaling cascade. When compared to sham-operated rats, HS-rats treated with vehicle displayed 
significant increases in the phosphorylation of BTK at $\mathrm{Tyr}^{223}$, indicating that BTK is activated in injured kidneys $(\mathrm{p}<0.05$; Figure $4 \mathrm{~A})$. Treatment with BTKi in HS-rats significantly abolished the increases in the phosphorylation of BTK at $\operatorname{Tyr}^{223}(\mathrm{p}<0.05$; Figure 4A). No significant differences were observed in the degree of phosphorylation (in the kidney) of BTK at $\operatorname{Tyr}^{223}$ between HS-rats treated with either acalabrutinib or fenebrutinib ( $\mathrm{p}>0.05$; Figure $\left.4 \mathrm{~A}\right)$. These data demonstrate that both BTKi abolish the activation of BTK caused by HS.

\section{Treatment with BTKi abolishes renal NF- $\mathrm{B} B$ activation in an acute $H S$ model}

The effect of BTK inhibition on the activation of the signaling events leading to the activation of NF- $\kappa \mathrm{B}$, were investigated in the kidney. When compared to sham-operated rats, HS-rats treated with vehicle had significant increases in the phosphorylation of IKK $\alpha / \beta$ at $\operatorname{Ser}^{176 / 180}$ $\left(\mathrm{p}<0.05\right.$; Figure 4B), phosphorylation of $\operatorname{I\kappa B} \alpha$ at $\operatorname{Ser}^{32 / 36}(p<0.05$; Figure $4 C)$ and the translocation of $\mathrm{p} 65$ to the nucleus ( $<<0.05$; Figure 4D). Treatment of HS-rats with either BTKi significantly abolished the increase in renal phosphorylation of $\operatorname{IKK} \alpha / \beta$ at $\operatorname{Ser}^{176 / 180}(p<0.05$; Figure 4B), the phosphorylation of $\operatorname{I\kappa B} \alpha$ at $\operatorname{Ser}^{32 / 36}(\mathrm{p}<0.05$; Figure 4C) and the nuclear translocation of p65 $(\mathrm{p}<0.05$; Figure 4D). No significant differences were observed in the degree of phosphorylation of IKK $\alpha / \beta$ at $\operatorname{Ser}^{176 / 180}$, phosphorylation of $\mathrm{I} \kappa \mathrm{B} \alpha$ at $\operatorname{Ser}^{32 / 36}$ and the translocation of p65 to the nucleus between HS-rats treated with either acalabrutinib or fenebrutinib ( $p>0.05$; Figures 4B-D). These data illustrate that both BTKi abolish the activation of NF- $\kappa \mathrm{B}$ caused by HS.

Treatment with BTKi abolishes renal NLRP3 and caspase 1 activation in an acute HS model Having discovered that BTKi significantly reduced the activation of NF- $\mathrm{BB}$ in the kidney of rats subjected to HS, we next analyzed the potential involvement of the NLRP3 inflammasome complex. When compared to sham-operated rats, HS-rats treated with vehicle exhibited a 
bioRxiv preprint doi: https://doi.org/10.1101/2021.09.23.460775; this version posted September $24,2021$. The copyright holder for this preprint (which was not certified by peer review) is the author/funder, who has granted bioRxiv a license to display the preprint in perpetuity. It is made available under aCC-BY-NC-ND 4.0 International license.

significantly increased expression of the NLRP3 inflammasome ( $<<0.05$; Figure 4E) and of the cleaved (activated) form of caspase $1(\mathrm{p}<0.05$; Figure 4F). Treatment of HS-rats with either BTKi acalabrutinib or fenebrutinib significantly inhibited the renal expression of NLRP3 $(\mathrm{p}<0.05$; Figure $4 \mathrm{E})$ and cleaved form of caspase $1(\mathrm{p}<0.05$; Figure $4 \mathrm{~F})$. No significant differences were observed in the degree of expression of the NLRP3 inflammasome and cleaved form of caspase 1 between HS-rats treated with either acalabrutinib or fenebrutinib ( $>0.05$; Figures 4E-F). These data demonstrate that both BTKi abolish the activation of the NLRP3 inflammasome and caspase 1 and the subsequent formation of IL-1 $\beta$.

BTK activation correlates with renal dysfunction, NF- $\kappa B$ and NLRP3 activation in an acute

\section{HS model}

Firstly, to address the question whether the degree of activation of BTK correlates with changes in renal function, we correlated the degree of phosphorylation of BTK at $\operatorname{Tyr}^{223}$ with serum creatinine (Figure 5A), urine creatinine (Figure 5B) and serum urea (Figure 5C). We found a highly significant positive correlation between the degree of BTK activation and the increases in serum creatinine (Figure 5A) and urea (Figure 5C), suggesting that BTK activation drives or precedes the renal dysfunction associated with hemorrhagic shock. No significant correlation was observed between BTK activation and the decrease in urine creatinine (Figure 5B). Secondly, the potential relationship between the degree of activation of BTK and alterations in the activation of NF-kB was also addressed by correlating the degree of phosphorylation of BTK at $\mathrm{Tyr}^{223}$ with the phosphorylation of IKK $\alpha / \beta$ at $\operatorname{Ser}^{176 / 180}$ (Figure 5D), the phosphorylation of $\mathrm{I} \kappa \mathrm{B} \alpha$ at $\operatorname{Ser}^{32 / 36}$ (Figure 5E) and the translocation of p65 (Figure 5F). We found a highly significant positive correlation between the degree of BTK activation and NF- $\kappa B$ activation when measured as IKK $\alpha / \beta$ phosphorylation at $\operatorname{Ser}^{176 / 180}$ (Figure 5D), IאB $\alpha$ phosphorylation at $\operatorname{Ser}^{32 / 36}$ (Figure 5E) and p65 translocation (Figure 5F). Thirdly, whether the 
bioRxiv preprint doi: https://doi.org/10.1101/2021.09.23.460775; this version posted September 24, 2021. The copyright holder for this preprint (which was not certified by peer review) is the author/funder, who has granted bioRxiv a license to display the preprint in perpetuity. It is made available under aCC-BY-NC-ND 4.0 International license.

degree of activation of BTK correlates with changes in the assembly and activation of the NLRP3 inflammasome was investigated by correlating the degree of phosphorylation of BTK at $\mathrm{Tyr}^{223}$ with the expression of NLRP3 (Figure 5G) and the cleaved (activated) form of caspase 1 (Figure 5H). We found a highly significant positive correlation between the degree of BTK activation and the NLRP3 inflammasome expression (Figure 5G) and the activation of caspase 1 (Figure 5H).

Treatment with acalabrutinib improves HS-induced circulatory failure in a chronic HS model When comparing acalabrutinib and fenebrutinib, both inhibitors were equally efficacious in the acute HS model but acalabrutinib has the advantage of being FDA approved; hence was investigated in a chronic HS model. Having demonstrated treatment with acalabrutinib improved blood pressure in an acute HS rat model, we wished to determine whether acalabrutinib would still be effective in a HS model in which the resuscitation period is prolonged to $24 \mathrm{~h}$. When compared to sham-operated rats, HS-rats treated with vehicle had significantly lower values of MAP recorded $24 \mathrm{~h}$ after the onset of resuscitation $(\mathrm{p}<0.05$; Figure $6 \mathrm{~A})$; highlighting that either cardiac dysfunction or excessive hypotension ${ }^{23}$ was still present. In contrast, the MAP values of HS-rats treated with acalabrutinib upon resuscitation were significantly higher even at $24 \mathrm{~h}$ after the onset of resuscitation [when compared with those of vehicle treated rats $(\mathrm{p}<0.05$; Figure $6 \mathrm{~A})]$. Administration of acalabrutinib to sham-operated rats had no significant effect on MAP ( $>00.05$; Figure 6A). There were no significant differences in HR between any of the four groups investigated ( $>>0.05$; Figure $6 B$ ).

Treatment with acalabrutinib attenuates HS-induced organ damage in a chronic HS model Having shown that treatment with acalabrutinib ameliorated the MODS associated with HS in an acute HS rat model, we examined whether this effect was sustained when the resuscitation 
bioRxiv preprint doi: https://doi.org/10.1101/2021.09.23.460775; this version posted September $24,2021$. The copyright holder for this preprint (which was not certified by peer review) is the author/funder, who has granted bioRxiv a license to display the preprint in perpetuity. It is made available under aCC-BY-NC-ND 4.0 International license.

period was extended to $24 \mathrm{~h}$. As with the acute HS model, when compared to sham-operated rats, rats subjected to chronic HS and treated with vehicle displayed significant increases in serum urea $(p<0.05$; Figure $7 A)$ and creatinine $(p<0.05$; Figure $7 B)$; indicating the development of renal dysfunction. When compared to sham-operated rats, vehicle treated HSrats exhibited significant increases in ALT ( $p<0.05$; Figure 7C) and AST ( $<<0.05$; Figure 7D) indicating the development of hepatic injury, whilst the significant increase in $\mathrm{LDH}(\mathrm{p}<0.05$; Figure 7E) confirmed general tissue injury. Treatment of HS-rats with acalabrutinib significantly attenuated the hepatic and general tissue injury caused by HS as shown by the decrease in serum parameter values $(\mathrm{p}<0.05$; Figures $7 \mathrm{C}-\mathrm{E})$. Treatment with acalabrutinib had no significant effect on renal dysfunction ( $>00.05$; Figures 7A-B). Administration of acalabrutinib to sham-operated rats had no significant effect on any of the parameters measured ( $>>0.05$; Figures 7A-E).

\section{Treatment with acalabrutinib reduces myeloperoxidase activity in a chronic HS model}

We next determined myeloperoxidase (MPO) activity in the lung and liver of rats subjected to HS as an indicator of neutrophil infiltration. When compared to sham-operated rats, HS-rats treated with vehicle showed a significant increase in MPO activity in the lung $(p<0.05$; Figure $7 F)$ and liver $(\mathrm{p}<0.05$; Figure $7 \mathrm{G})$. Treatment with acalabrutinib in HS-rats significantly attenuated the rises in pulmonary (Figure 7F) and hepatic (Figure 7G) MPO activity $(\mathrm{p}<0.05)$, suggesting reduced neutrophil recruitment and inflammation. Administration of acalabrutinib to sham-operated rats had no significant effect on both pulmonary and hepatic MPO activity ( $>0.05$; Figures 7F-G). 


\section{DISCUSSION}

This study reports for the first time that inhibition of BTK activity attenuates organ injury/dysfunction and circulatory failure in acute (Figures 2 and 3) and chronic (Figures 6 and 7) rat models of HS. Having shown that BTK gene expression is significantly elevated in leukocytes of trauma patients (Figure 1), we used a reverse translational approach to investigate whether pharmacological intervention with acalabrutinib and fenebrutinib, ameliorates the MODS associated with HS in a well-established rat model. Administration of either an irreversible (acalabrutinib) or a reversible (fenebrutinib) inhibitor of BTK activity significantly attenuated the fall in blood pressure caused by HS (Figures 2 acute and 6 chronic). Thus, BTKi reduces the delayed vascular decompensation which is (in part) secondary to the expression of inducible nitric oxide synthase $\mathrm{e}^{23}$. Moreover, BTKi significantly attenuated the renal dysfunction, hepatic injury and neuromuscular injury caused by HS (Figures 3 acute and 7 chronic). This is consistent with published studies which demonstrated a reduction in disease severity following BTK inhibition in animal models of lupus nephritis ${ }^{24,25}$, warm hepatic ischemia and reperfusion ${ }^{26}$, acute lung injury ${ }^{27-29}$ and sepsis ${ }^{9}$.

What, then, are the mechanisms by which BTKi attenuate HS-associated organ injury/dysfunction? Western blot analysis revealed that acute HS resulted in a significant increase in BTK activity in the injured kidney (Figure 4). Most notably, this activation of BTK positively correlated with serum creatinine and urea (Figure 5), indicating that activation of BTK is associated with the renal dysfunction in hemorrhagic shock. Indeed, inhibition of BTK activity with acalabrutinib or fenebrutinib in the kidney of shocked animals decreases the renal dysfunction in hemorrhagic shock, suggesting that activation of BTK plays a pivotal role in the pathophysiology of the renal dysfunction in hemorrhagic shock. Other research groups have shown a positive correlation between BTK expression and creatinine in patients with IgA 
bioRxiv preprint doi: https://doi.org/10.1101/2021.09.23.460775; this version posted September 24, 2021. The copyright holder for this preprint (which was not certified by peer review) is the author/funder, who has granted bioRxiv a license to display the preprint in perpetuity. It is made available under aCC-BY-NC-ND 4.0 International license.

nephropathy ${ }^{30}$ and diabetic nephropathy ${ }^{31}$. Our finding is the first in the field of trauma and hemorrhagic shock.

There is good evidence that BTK activation precedes the activation of NF- $\kappa B$ through TLR signaling $^{32}$. Indeed, trauma results in elevated NF- $\kappa B$ translocation to the nucleus ${ }^{19-22}$. Inhibition of BTK activity with acalabrutinib or fenebrutinib reduced the activation of NF- $\mathrm{B}$ in the kidney (Figure 4). We also found a significant positive correlation between the activation of BTK and the phosphorylation of IKK $\alpha / \beta$ at $\operatorname{Ser}^{176 / 180}$, phosphorylation of IKB $\alpha$ at $\operatorname{Ser}^{32 / 36}$ and translocation of p65 (Figure 5). This may suggest that inhibiting the activation of NF- $\mathrm{B}$ contributes to the observed beneficial effects of acalabrutinib and fenebrutinib in traumahemorrhage; as NF- $\mathrm{kB}$ activation is involved in the regulation of immunological and inflammatory responses. Activation of NF- $\mathrm{kB}$ drives the formation of several pro- and antiinflammatory mediators which include cytokines, chemokines and enzymes ${ }^{33}$. As part of a positive feedback loop, these mediators can activate $\mathrm{NF}-\kappa \mathrm{B}$ and its upstream signaling components, further amplifying and perpetuating the inflammatory responses mediated by NF$\kappa \mathrm{B}$ which can lead to increased endothelial permeability, tissue hypoperfusion/hypoxia, tissue injury and ultimately MODS ${ }^{11}$. It should be noted that the inhibition of BTK activity in CLPsepsis also reduced activation of $\mathrm{NF}-\mathrm{\kappa B}^{9}$.

There is also good evidence that BTK activation influences the assembly and activation of the NLRP3 inflammasome in rodents and humans ${ }^{34-36}$. NLRP3 inflammasome activation drives the production of IL-1 $\beta$ which plays a crucial role in the systemic inflammation and/or organ dysfunction in trauma ${ }^{22}$. Inhibition of BTK activity with acalabrutinib or fenebrutinib reduces both the assembly and subsequent activation of the NLRP3 inflammasome in the kidney (Figure 4). We also discovered a significant positive correlation between the activation of BTK 
and both the activation of NLRP3 and caspase 1 (Figure 5). This may suggest that inhibiting the activation of the NLRP3 inflammasome contributes to the observed protective effects of acalabrutinib and fenebrutinib in trauma-hemorrhage by lowering the pro-inflammatory effects of IL-1 $\beta$ and resulting tissue inflammation. This is due to IL-1 $\beta$ not only directly causing inflammation but also stimulating the expression of several pro-inflammatory adhesion molecules and cytokines which further exacerbates the inflammatory response ${ }^{37}$. It should be noted that the inhibition of BTK activity in CLP-sepsis also reduced activation of NLRP3 and cleavage of pro-caspase 1 to caspase $1^{9}$.

The sterile inflammation caused by HS drives leukocyte recruitment to the tissues and is secondary to the activation of NF- $\mathrm{KB}$ and NLRP3 and their transcriptional regulation of proinflammatory cytokines ${ }^{38-40}$. Moreover, the expression of adhesion molecules present on leukocytes and endothelial cells is regulated by NF- $\kappa \mathrm{B}$ and permits leukocyte extravasation from the circulation to the site of injury ${ }^{41}$. As neutrophils play a key role in HS-associated pulmonary and hepatic inflammation, we evaluated the degree of neutrophil recruitment (measured as MPO activity) in the lung and liver ${ }^{42,43}$. HS resulted in a significant increase in both pulmonary and hepatic MPO activity which was attenuated by the treatment of HS-rats with acalabrutinib (Figure 7). Following ICAM-1 binding on endothelial cells and subsequent tissue recruitment, neutrophils undergo degranulation and release pro-inflammatory mediators $^{44,45}$. These mediators (e.g. cytokines, reactive oxygen species and MPO) can contribute to inflammation by exerting direct cytotoxic cellular effects at the local site; subsequently leading to organ dysfunction and potential mortality following HS and resuscitation ${ }^{3,46}$. As we have demonstrated in the acute HS model that treatment with BTKi attenuates both NF- $\kappa \mathrm{B}$ and NLRP3 activation, it can be implied that the decreased recruitment 
bioRxiv preprint doi: https://doi.org/10.1101/2021.09.23.460775; this version posted September 24, 2021. The copyright holder for this preprint (which was not certified by peer review) is the author/funder, who has granted bioRxiv a license to display the preprint in perpetuity. It is made available under aCC-BY-NC-ND 4.0 International license.

of neutrophils and lowered inflammation is secondary to this reduced activation of NF- $\kappa \mathrm{B}$ and NLRP3.

Our results and conclusions are supported by findings in patient cohorts with either COVID19 or sepsis where BTK has been proposed to play a role in disease pathogenesis; both diseases featuring the hallmarks of excessive systemic inflammation similar to those seen in traumaassociated MODS ${ }^{15,47}$. The beneficial effects of acalabrutinib in COVID-19 patients, as measured by the determination of biomarkers of inflammation, oxygenation and clinical status, imply that BTK activation plays a role in the pathology ${ }^{15}$. Whilst Parnell and colleagues did not investigate pharmacological intervention with BTKi in patients with sepsis, reanalysis of microarray data (Gene Expression Omnibus Dataset Number GDS4971) revealed an increased expression (in whole blood) of BTK in septic non-survivors compared to septic survivors; highlighting the potential for BTK to be a predictor of mortality ${ }^{10}$.

\section{LIMITATIONS OF THE STUDY}

Although acalabrutinib and fenebrutinib displayed some striking, beneficial effects in the HS models, there are study limitations which should be considered. Further long-term survival experiments are needed to verify that the observed early reduction in MODS does, indeed, translate to improved outcome and ultimately reduced mortality. In our study, organ injury and dysfunction were used as surrogate markers for mortality (as the determination of mortality is not allowed by our respective ethics and/or Home Office licenses). Therefore, care must be taken when interpreting our pre-clinical results and extrapolating them to the clinical scenario. In addition, future studies in larger animals and/or higher species may be useful to confirm efficacy and to further investigate the mechanism of action (e.g. blood gas analysis and microcirculatory effects) of BTKi in HS. As BTK is primarily expressed in cells of 
bioRxiv preprint doi: https://doi.org/10.1101/2021.09.23.460775; this version posted September 24, 2021. The copyright holder for this preprint (which was not certified by peer review) is the author/funder, who has granted bioRxiv a license to display the preprint in perpetuity. It is made available under aCC-BY-NC-ND 4.0 International license.

hematopoietic lineage (except T-lymphocytes, plasma cells and natural killer cells), it is likely that the increase in BTK activity measured in the kidneys of rats with HS was secondary to the infiltration of these organs by invading immune cells rather than an increase in parenchymal renal tissue (where no expression of BTK has been reported). Therefore, it is possible that inhibition of BTK leads to decreased recruitment of leukocytes into the kidney (as a result of reduced NF- $\kappa$ B and NLRP3 activation) and subsequently to lower levels of BTK activation in the kidney. Furthermore, clinical studies with large cohorts of trauma patients are needed to robustly examine the relationship between BTK activity and clinical outcomes in humans.

\section{CONCLUSIONS}

In conclusion, we report here for the first time that treatment with either the irreversible BTKi acalabrutinib or the reversible BTKi fenebrutinib reduces the organ injury/dysfunction and circulatory failure caused by severe hemorrhage in the rat; highlighting a role of BTK in disease pathogenesis. Moreover, experimental trauma-hemorrhage results in a significant upregulation of BTK in the kidney. Administration of either BTKi subsequently attenuates the degree of activation of BTK as well as the activation of NF- $\mathrm{BB}$ and the NLRP3 inflammasome (measured in the kidney), both of which are key drivers of local and systemic inflammation. Notably, no significant differences were found between the two structurally and mechanistically different inhibitors, suggesting that the observed beneficial effects in experimental trauma-hemorrhage are most likely due to a drug class related effect. Thus, we propose that BTKi may be repurposed for the use in trauma patients to lower the organ injury and inflammation caused by severe hemorrhage and resuscitation. 


\section{REFERENCES}

1. World Health Organization. Injuries and Violence: The Facts 2014.; 2014. Accessed May 6, 2021.www.who.int/healthinfo/global_burden_disease/projections/en/

2. Curry N, Hopewell S, Dorée C, Hyde C, Brohi K, Stanworth S. The acute management of trauma hemorrhage: A systematic review of randomized controlled trials. Critical Care. 2011;15(2):1-10. doi:10.1186/cc10096

3. Dewar D, Moore FA, Moore EE, Balogh Z. Postinjury multiple organ failure. Injury. 2009;40(9):912-918. doi:10.1016/j.injury.2009.05.024

4. Lord JM, Midwinter MJ, Chen YF, et al. The systemic immune response to trauma: An overview of pathophysiology and treatment. The Lancet. 2014;384(9952):1455-1465. doi:10.1016/S0140-6736(14)60687-5

5. Vetrie D, Vořechovský I, Sideras $\mathrm{P}$, et al. The gene involved in X-linked agammaglobulinaemia is a member of the src family of protein-tyrosine kinases. Nature. 1993;361(6409):226-233. doi:10.1038/361226a0

6. Mohamed AJ, Yu L, Bäckesjö CM, et al. Bruton's tyrosine kinase (Btk): Function, regulation, and transformation with special emphasis on the PH domain. Immunological Reviews. 2009;228(1):58-73. doi:10.1111/j.1600-065X.2008.00741.X

7. Weber ANR, Bittner Z, Liu X, Dang TM, Radsak MP, Brunner C. Bruton's tyrosine kinase: An emerging key player in innate immunity. Frontiers in Immunology. 2017;8(NOV):1454. doi:10.3389/fimmu.2017.01454

8. Xiao W, Mindrinos MN, Seok J, et al. A genomic storm in critically injured humans. The Journal of Experimental Medicine. 2011;208(13):2581. doi:10.1084/JEM.20111354 
9. O'Riordan CE, Purvis GSD, Collotta D, et al. Bruton's Tyrosine Kinase Inhibition Attenuates the Cardiac Dysfunction Caused by Cecal Ligation and Puncture in Mice. Frontiers in Immunology. 2019;10:2129. doi:10.3389/fimmu.2019.02129

10. O'Riordan CE, Purvis GSD, Collotta D, et al. X-Linked Immunodeficient Mice With No Functional Bruton's Tyrosine Kinase Are Protected From Sepsis-Induced Multiple Organ Failure. Frontiers in Immunology. 2020;11:581758. doi:10.3389/fimmu.2020.581758

11. Liu SF, Malik AB. NF- $\kappa B$ activation as a pathological mechanism of septic shock and inflammation. American Journal of Physiology - Lung Cellular and Molecular Physiology. 2006;290(4). doi:10.1152/ajplung.00477.2005

12. Coldewey SM, Rogazzo M, Collino M, Patel NSA, Thiemermann C. Inhibition of IкB kinase reduces the multiple organ dysfunction caused by sepsis in the mouse. Disease Models \& Mechanisms. 2013;6(4):1031. doi:10.1242/DMM.012435

13. Sordi R, Chiazza F, Johnson FL, et al. Inhibition of IкB kinase attenuates the organ injury and dysfunction associated with hemorrhagic shock. Molecular Medicine. 2015;21(1):563-575. doi:10.2119/molmed.2015.00049

14. Nicolson PLR, Welsh JD, Chauhan A, Thomas MR, Kahn ML, Watson SP. A rationale for blocking thromboinflammation in COVID-19 with Btk inhibitors. Platelets. 2020;31(5):685-690. doi:10.1080/09537104.2020.1775189

15. Roschewski M, Lionakis MS, Sharman JP, et al. Inhibition of Bruton tyrosine kinase in patients with severe COVID-19. Science Immunology. 2020;5(48). doi:10.1126/SCIIMMUNOL.ABD0110

16. Soresina A, Moratto D, Chiarini | Marco, et al. Two X-linked agammaglobulinemia patients develop pneumonia as COVID-19 manifestation but recover. Pediatr Allergy Immunol. 2020;00:1-5. doi:10.1111/pai.13263 
17. Burger JA. Bruton Tyrosine Kinase Inhibitors: Present and Future. Cancer Journal (United States). 2019;25(6):386-393. doi:10.1097/PPO.0000000000000412

18. Liu X, Zhang J, Han W, et al. Inhibition of BTK protects lungs from traumahemorrhagic shock-induced injury in rats. Molecular Medicine Reports. 2017;16(1):192-200. doi:10.3892/mmr.2017.6553

19. Sordi R, Chiazza F, Collotta D, et al. Resolvin D1 Attenuates the Organ Injury Associated With Experimental Hemorrhagic Shock. Annals of Surgery. 2021;273(5):1012-1021. doi:10.1097/sla.0000000000003407

20. Sordi R, Nandra KK, Chiazza F, et al. Artesunate protects against the organ injury and dysfunction induced by severe hemorrhage and resuscitation. Annals of Surgery. Published online 2017. doi:10.1097/SLA.0000000000001664

21. Yamada N, Martin LB, Zechendorf E, et al. Novel Synthetic, Host-defense Peptide Protects Against Organ Injury/Dysfunction in a Rat Model of Severe Hemorrhagic Shock. Annals of Surgery. Published online 2018. doi:10.1097/SLA.0000000000002186

22. Martin L, Patel NM, 2\# M, et al. The inhibition of Macrophage Migration Inhibitory Factor by ISO-1 attenuates trauma-induced multi organ dysfunction in rats. medRxiv. Published online April 29, 2021:2021.04.28.21255719. doi:10.1101/2021.04.28.21255719

23. Thiemermann C, Szabo C, Mitchell JA, Vane JR. Vascular hyporeactivity to vasoconstrictor agents and hemodynamic decompensation in hemorrhagic shock is mediated by nitric oxide. Proceedings of the National Academy of Sciences of the United States of America. 1993;90(1):267-271. doi:10.1073/pnas.90.1.267 
24. Chalmers SA, Doerner J, Bosanac T, et al. Therapeutic Blockade of Immune ComplexMediated Glomerulonephritis by Highly Selective Inhibition of Bruton's Tyrosine Kinase. Scientific Reports. 2016;6. doi:10.1038/srep26164

25. Chalmers SA, Glynn E, Garcia SJ, et al. BTK inhibition ameliorates kidney disease in spontaneous lupus nephritis. Clinical Immunology. 2018;197:205-218. doi:10.1016/j.clim.2018.10.008

26. Palumbo T, Nakamura K, Lassman C, et al. Bruton Tyrosine Kinase Inhibition Attenuates Liver Damage in a Mouse Warm Ischemia and Reperfusion Model. Transplantation. 2017;101(2):322-331. doi:10.1097/TP.0000000000001552

27. Krupa A, Fol M, Rahman M, et al. Silencing bruton's tyrosine kinase in alveolar neutrophils protects mice from LPS/immune complex-induced acute lung injury. American Journal of Physiology - Lung Cellular and Molecular Physiology. 2014;307(6):L435-L448. doi:10.1152/ajplung.00234.2013

28. Zhou P, Ma B, Xu S, et al. Knockdown of Burton's tyrosine kinase confers potent protection against sepsis-induced acute lung injury. Cell biochemistry and biophysics. 2014;70(2):1265-1275. doi:10.1007/s12013-014-0050-1

29. Florence JM, Krupa A, Booshehri LM, Davis SA, Matthay MA, Kurdowska AK. Inhibiting bruton's tyrosine kinase rescues mice from lethal influenza-induced acute lung injury. American Journal of Physiology - Lung Cellular and Molecular Physiology. 2018;315(1):L52-L58. doi:10.1152/ajplung.00047.2018

30. Wei J, Wang Y, Qi X, Wu Y. Enhanced Bruton's tyrosine kinase activity in the kidney of patients with IgA nephropathy. International Urology and Nephrology. 2021;53(7):1399. doi:10.1007/S11255-020-02733-2

31. Zhao J, Chen J, Li Y-Y, Xia L-L, Wu Y-G. Bruton's tyrosine kinase regulates macrophage-induced inflammation in the diabetic kidney via NLRP3 inflammasome 
activation. International Journal of Molecular Medicine. 2021;48(3). doi:10.3892/IJMM.2021.5010

32. Jefferies CA, Doyle S, Brunner C, et al. Bruton's tyrosine kinase is a Toll/interleukin-1 receptor domain-binding protein that participates in nuclear factor $\kappa \mathrm{B}$ activation by tolllike receptor 4. Journal of Biological Chemistry. 2003;278(28):26258-26264. doi:10.1074/jbc.M301484200

33. Senftleben U, Karin M. The IKK/NF-kappa B pathway. Crit Care Med. 2002;30:S18S26. Accessed May 11, 2021. https://pubmed.ncbi.nlm.nih.gov/11782557/

34. Ito M, Shichita T, Okada M, et al. Bruton's tyrosine kinase is essential for NLRP3 inflammasome activation and contributes to ischaemic brain injury. Nature Communications. 2015;6(1):1-11. doi:10.1038/ncomms8360

35. Liu X, Pichulik T, Wolz OO, et al. Human NACHT, LRR, and PYD domain-containing protein 3 (NLRP3) inflammasome activity is regulated by and potentially targetable through Bruton tyrosine kinase. Journal of Allergy and Clinical Immunology. 2017;140(4):1054-1067.e10. doi:10.1016/j.jaci.2017.01.017

36. Bittner ZA, Liu X, Shankar S, et al. BTK operates a phospho-tyrosine switch to regulate NLRP3 inflammasome activity. bioRxiv. Published online June 25, 2020:864702. doi:10.1101/864702

37. Dinarello CA. Biologic basis for interleukin-1 in disease. Blood. 1996;87(6):2095-2147. doi:10.1182/blood.v87.6.2095.bloodjournal8762095

38. Chen CC, Manning AM. Transcriptional regulation of endothelial cell adhesion molecules: A dominant role for NF-кB. Agents and Actions Supplements. 1995;47:135141. doi:10.1007/978-3-0348-7343-7_12 
39. Collins T, Read MA, Neish AS, Whitley MZ, Thanos D, Maniatis T. Transcriptional regulation of endothelial cell adhesion molecules: NF-kB and cytokine-inducible enhancers. The FASEB Journal. 1995;9(10):899-909.

40. Campbell SJ, Anthony DC, Oakley F, et al. Hepatic Nuclear Factor $\kappa$ B Regulates Neutrophil Recruitment to the Injured Brain. Journal of Neuropathology \& Experimental Neurology. 2008;67(3):223-230. doi:10.1097/NEN.0B013E3181654957

41. Hayden MS, Ghosh S. NF-кB in immunobiology. Cell Research 2011 21:2. 2011;21(2):223-244. doi:10.1038/cr.2011.13

42. Botha AJ, Moore FA, Moore EE, Kim FJ, Banerjee A, Peterson VM. Postinjury neutrophil priming and activation: An early vulnerable window. Surgery. 1995;118(2):358-365. doi:10.1016/S0039-6060(05)80345-9

43. Partrick D, Moore F, Moore E, Barnett Jr C, Silliman C. Neutrophil priming and activation in the pathogenesis of postinjury multiple organ failure. New Horiz. 1996;4(2):194-210. $\quad$ Accessed $\quad$ May $\quad 12, \quad 2021$. https://pubmed.ncbi.nlm.nih.gov/8774796/

44. Sauaia A, Moore FA, Moore EE. Postinjury Inflammation and Organ Dysfunction. Critical Care Clinics. 2017;33(1):167-191. doi:10.1016/j.ccc.2016.08.006

45. Olanders K, Sun Z, Börjesson A, et al. The effect of intestinal ischemia and reperfusion injury on ICAM-1 expression, endothelial barrier function, neutrophil tissue influx, and protease inhibitor levels in rats. Shock. 2002;18(1):86-92. doi:10.1097/00024382200207000-00016

46. Zhang Y, Zhang J, Korff S, Ayoob F, Vodovotz Y, Billiar TR. Delayed neutralization of interleukin 6 reduces organ injury, selectively suppresses inflammatory mediator, and partially normalizes immune dysfunction following trauma and hemorrhagic shock. Shock (Augusta, Ga). 2014;42(3):218-227. doi:10.1097/SHK.0000000000000211 
bioRxiv preprint doi: https://doi.org/10.1101/2021.09.23.460775; this version posted September 24, 2021. The copyright holder for this

preprint (which was not certified by peer review) is the author/funder, who has granted bioRxiv a license to display the preprint in perpetuity. It is made available under aCC-BY-NC-ND 4.0 International license.

47. Parnell GP, Tang BM, Nalos M, et al. Identifying key regulatory genes in the whole blood of septic patients to monitor underlying immune dysfunctions. Shock. 2013;40(3):166-174. doi:10.1097/SHK.0b013e31829ee604 


\section{FIGURE LEGENDS}

Figure 1: BTK gene expression is elevated in trauma patients. Original data was obtained from the Gene Expression Omnibus under dataset accession number GSE36809 which was published by Xiao and colleagues ${ }^{8}$. RNA was extracted from whole blood leukocytes over a 28-day time course from trauma patients $(n=167)$ and matched healthy controls $(n=37)$. Data were reanalyzed for BTK gene expression. Data are expressed as mean \pm SEM. Statistical analysis was performed using one-way ANOVA followed by a Bonferroni's post-hoc test. *p $<0.05$ denoted statistical significance.

Figure 2: Treatment with BTKi improves HS-induced circulatory failure in an acute HS model. (A) Mean arterial pressure (MAP) was measured from the completion of surgery to the termination of the experiment for vehicle and BTKi treated (acalabrutinib, ACA; fenebrutinib, FEN) rats. (B) MAP values at the end of the resuscitation period (330 mins). Data are expressed as mean \pm SEM of 8-10 animals per group. Statistical analysis was performed using two-way ANOVA followed by a Bonferroni's post-hoc test. ${ }^{*} \mathrm{p}<0.05$ Sham + vehicle vs. HS + vehicle; $\# \mathrm{p}<0.05 \mathrm{HS}+$ vehicle vs. HS + BTKi (ACA or FEN).

\section{Figure 3: Treatment with BTKi attenuates HS-induced organ damage in an acute HS}

model. Rats were subjected to hemorrhagic shock (HS) and $4 \mathrm{~h}$ after resuscitation, levels of serum (A) urea, (B) creatinine, (C) alanine aminotransferase (ALT), (D) aspartate aminotransferase (AST), (E) creatine kinase (CK) and (F) lactate dehydrogenase (LDH) were determined in vehicle and BTKi treated (acalabrutinib, ACA; fenebrutinib, FEN) rats. Shamoperated rats were used as control. Data are expressed as mean \pm SEM of 8-10 animals per group. Statistical analysis was performed using one-way ANOVA followed by a Bonferroni's post-hoc test. $* \mathrm{p}<0.05$ denoted statistical significance. 
Figure 4: Treatment with BTKi attenuates BTK, NF-אB and NLRP3 activation in an acute HS model. (A) The phosphorylation of BTK at $\mathrm{Tyr}^{223}$, (B) the phosphorylation of $\mathrm{IKK} \alpha / \beta$ at $\operatorname{Ser}^{176 / 180}$, (C) the phosphorylation of $\mathrm{I \kappa B} \alpha$ at $\mathrm{Ser}^{32 / 36}$, (D) the nuclear translocation of p65, (E) the activation of NLRP3 and (F) the cleaved (activated) form of caspase 1 of vehicle and BTKi treated (acalabrutinib, ACA; fenebrutinib, FEN) rats were determined by western blotting in the kidney. Protein expression was measured as relative optical density (O.D.) and normalized to the sham band. Data are expressed as mean \pm SEM of five animals per group. Statistical analysis was performed using one-way ANOVA followed by a Bonferroni's posthoc test. ${ }^{*} \mathrm{p}<0.05$ denoted statistical significance.

Figure 5: BTK activation correlates with renal dysfunction, NF-кB and NLRP3 activation in an acute HS model. Linear regression analysis of (A) phosphorylation of BTK at $\mathrm{Tyr}^{223}$ vs. serum creatinine, (B) phosphorylation of BTK at $\operatorname{Tyr}^{223}$ vs. urine creatinine, (C)

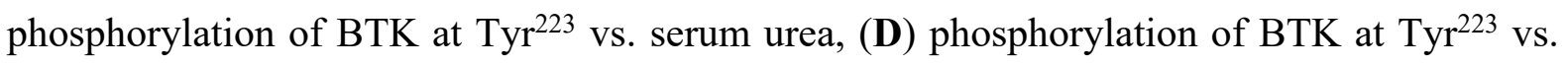
phosphorylation of $\mathrm{IKK} \alpha / \beta$ at $\mathrm{Ser}^{176 / 180}$, (E) phosphorylation of BTK at $\operatorname{Tyr}^{223}$ vs. phosphorylation of $\mathrm{I} \kappa \mathrm{B} \alpha$ at $\operatorname{Ser}^{32 / 36}(\mathbf{F})$ phosphorylation of BTK at $\mathrm{Tyr}^{223}$ vs. translocation of p65 (G) phosphorylation of BTK at $\operatorname{Tyr}^{223}$ vs. expression of NLRP3 and (H) phosphorylation of BTK at $\mathrm{Tyr}^{223}$ vs. expression of the cleaved form of caspase 1. Data are expressed as raw individual values of five animals per group. Statistical analysis was performed using simple linear regression to calculate the $r^{2}$ value, Pearson correlation coefficient test to calculate the $r$ value and a two-tailed t-test to calculate the $\mathrm{p}$-value. ${ }^{*} \mathrm{p}<0.05$ denoted statistical significance.

Figure 6: Treatment with acalabrutinib improves HS-induced circulatory failure in a chronic HS model. (A) Mean arterial pressure (MAP) and (B) heart rate (HR) were measured 
bioRxiv preprint doi: https://doi.org/10.1101/2021.09.23.460775; this version posted September 24, 2021. The copyright holder for this preprint (which was not certified by peer review) is the author/funder, who has granted bioRxiv a license to display the preprint in perpetuity. It is made available under aCC-BY-NC-ND 4.0 International license.

$24 \mathrm{~h}$ post resuscitation for vehicle and acalabrutinib (ACA) treated rats. Sham-operated rats were used as control. Data are expressed as mean \pm SEM of 9-10 animals per group. Statistical analysis was performed using one-way ANOVA followed by a Bonferroni's post-hoc test. ${ }^{*} \mathrm{p}<0.05$ denoted statistical significance.

Figure 7: Treatment with acalabrutinib attenuates HS-induced organ damage and myeloperoxidase activity in a chronic HS model. Rats were subjected to hemorrhagic shock (HS) and $24 \mathrm{~h}$ after resuscitation, levels of serum (A) urea, (B) creatinine, (C) alanine aminotransferase (ALT), (D) aspartate aminotransferase (AST) and (E) lactate dehydrogenase (LDH) and myeloperoxidase (MPO) activity in the (F) lung and (G) liver were determined for vehicle and acalabrutinib (ACA) treated rats. Sham-operated rats were used as control. Data are expressed as mean \pm SEM of 9-10 animals per group. Statistical analysis was performed using one-way ANOVA followed by a Bonferroni's post-hoc test. ${ }^{*} \mathrm{p}<0.05$ denoted statistical significance.

\section{LIST OF SUPPLEMENTAL DIGITAL CONTENT}

Supplemental digital content: BTK in Trauma Supplemental.pdf 


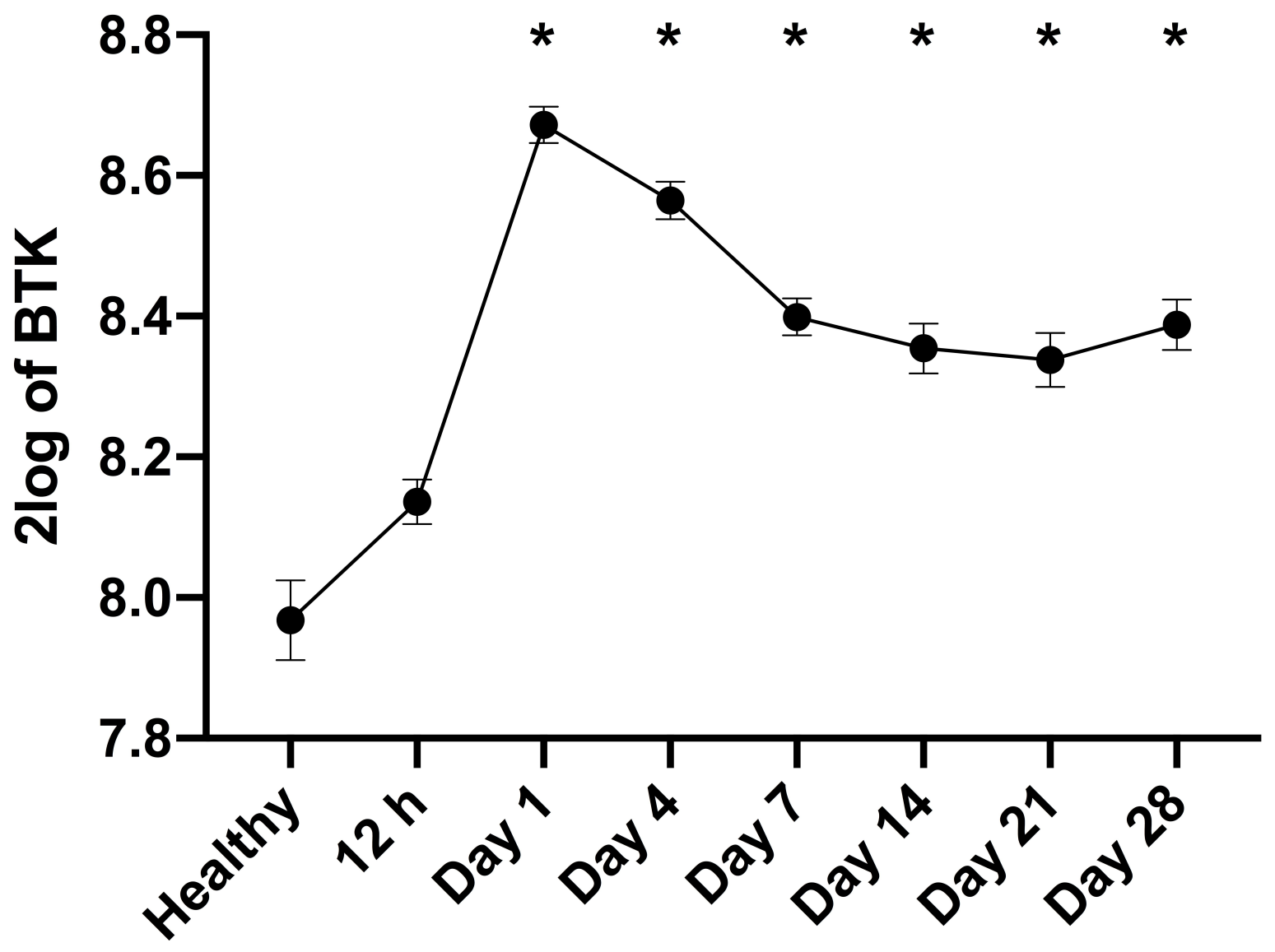


A

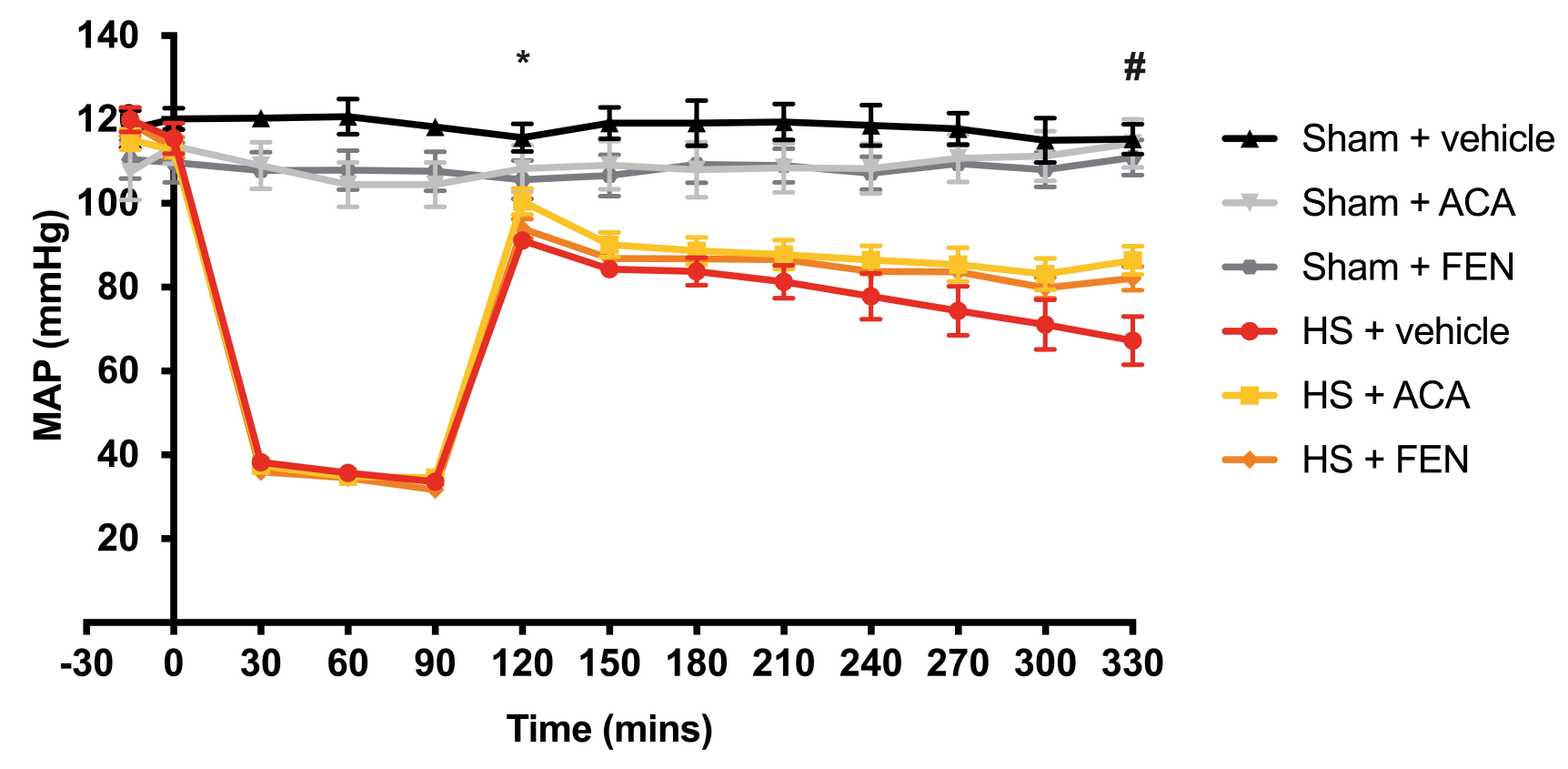

B

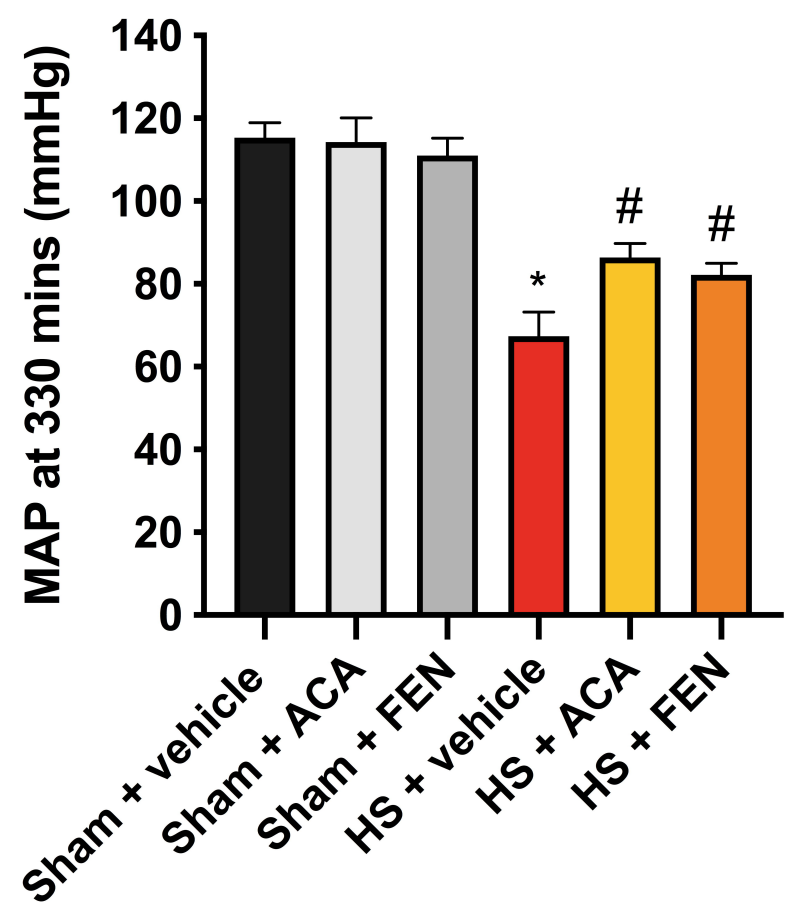




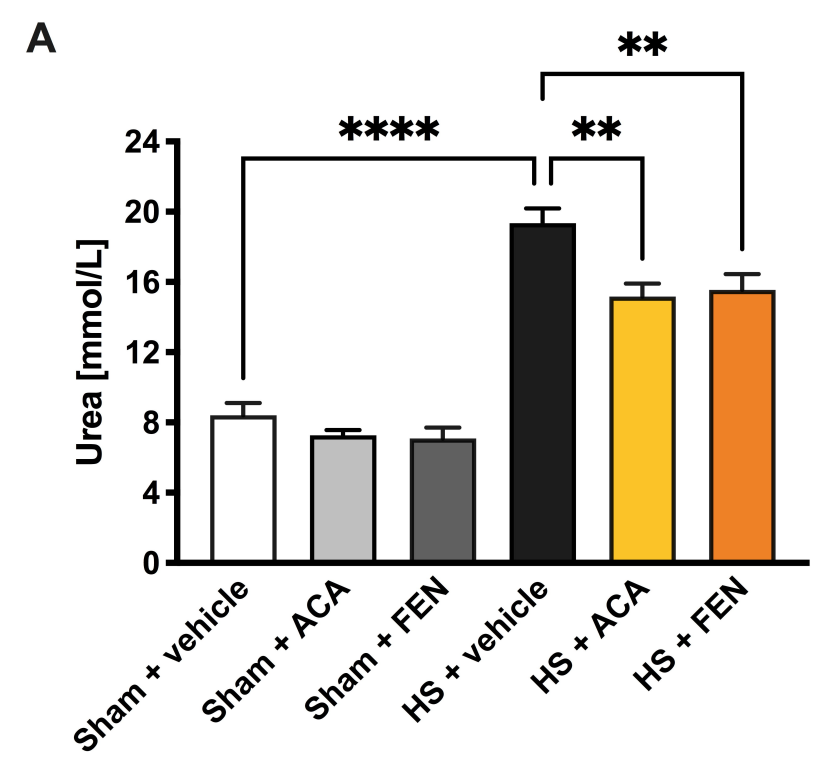

B

****

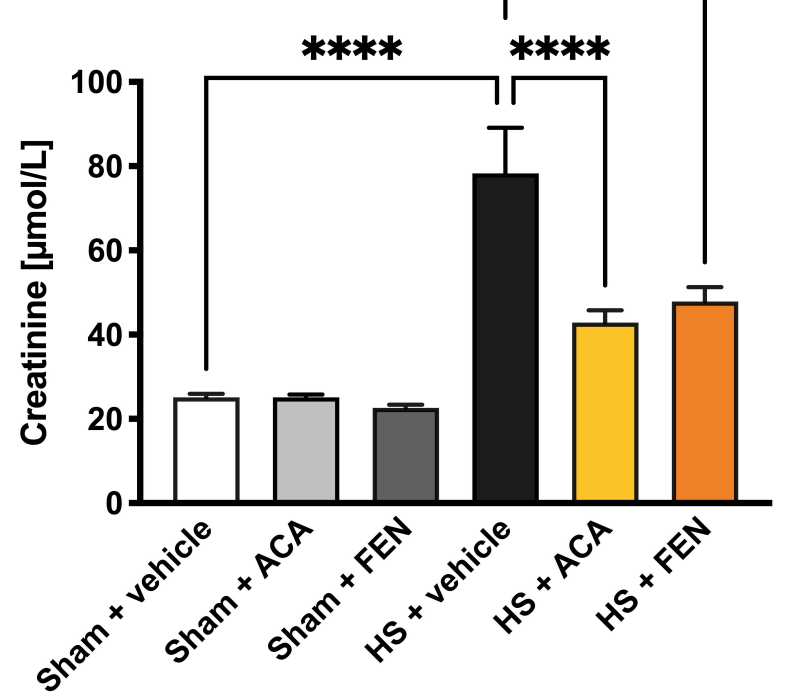

C

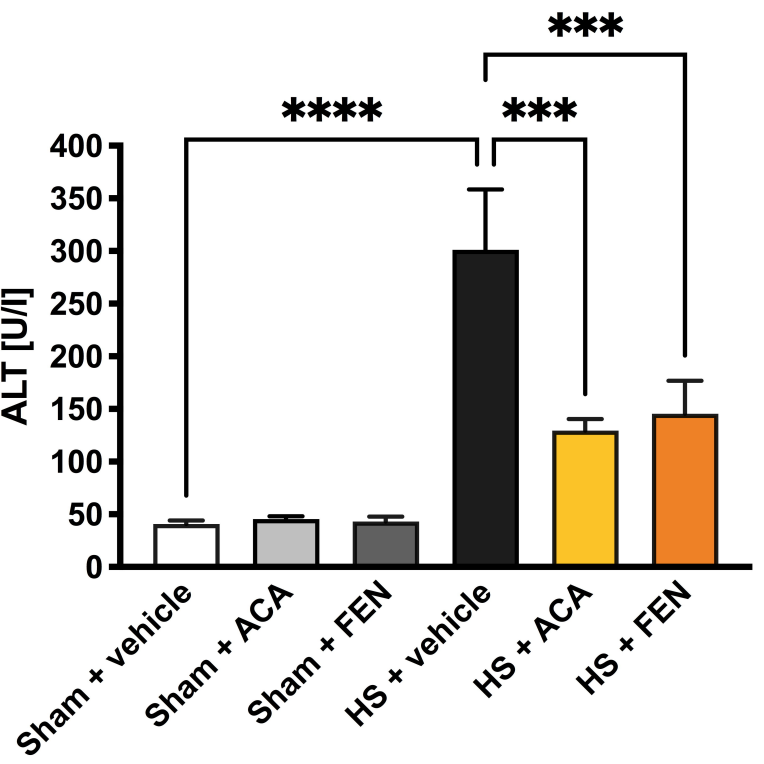

D

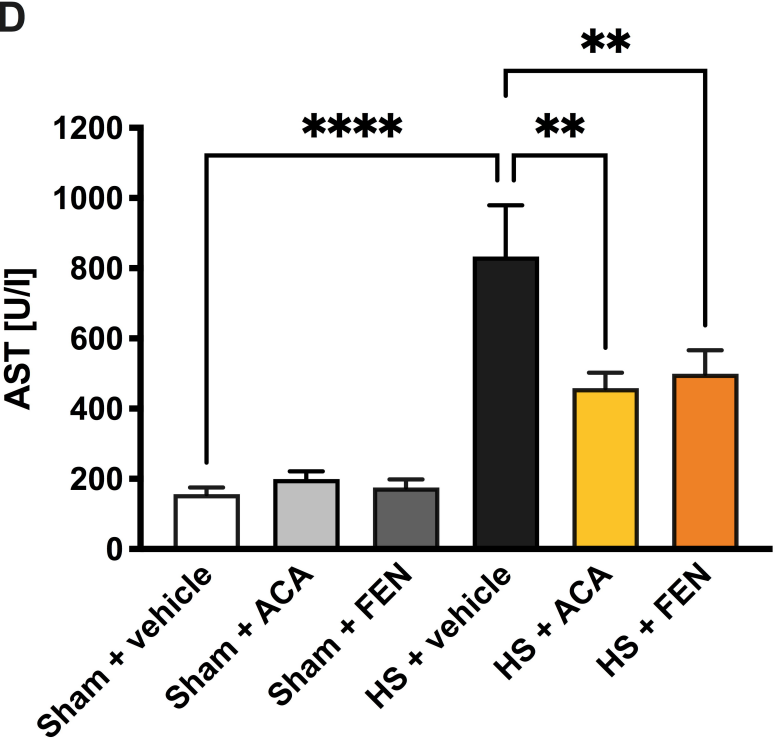

E
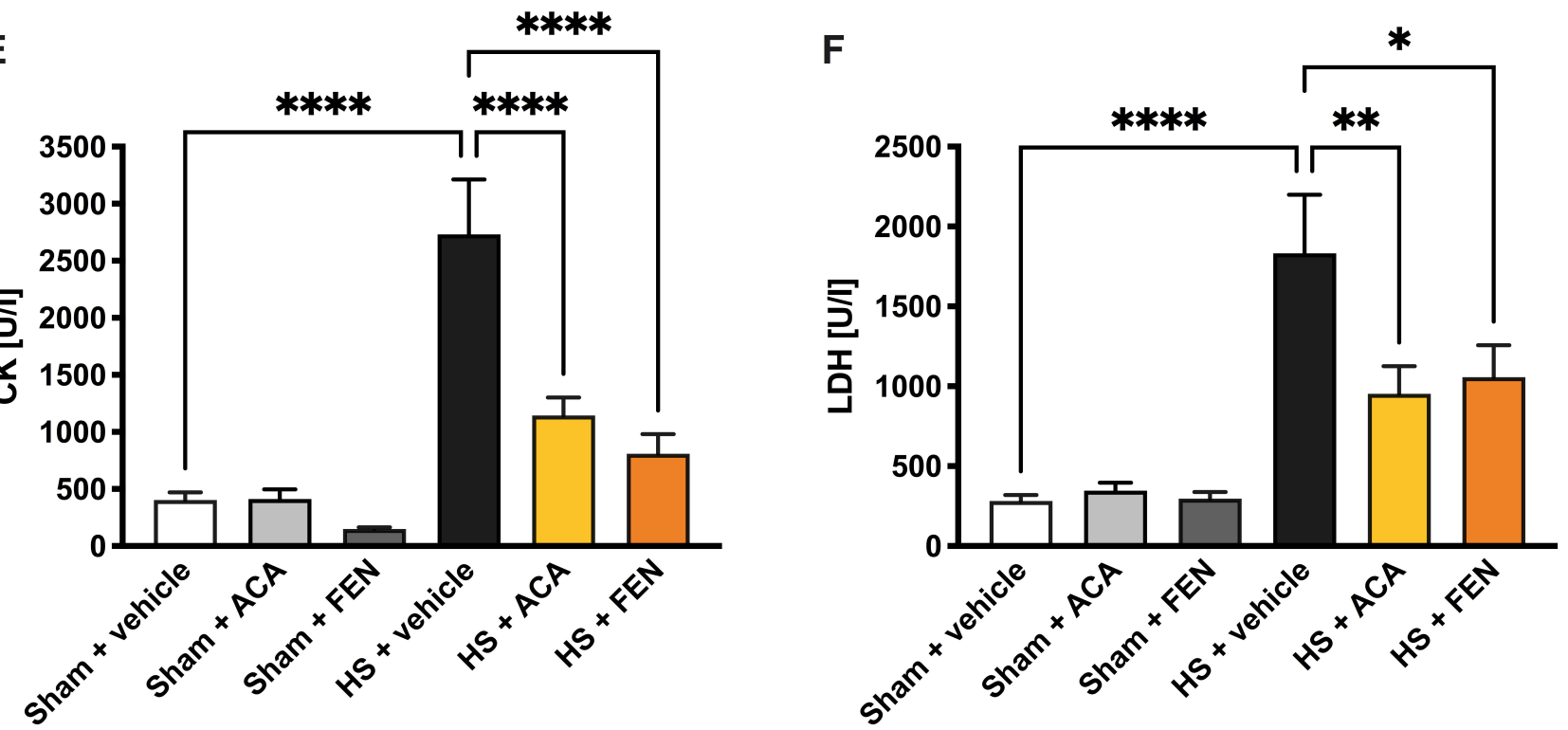
A

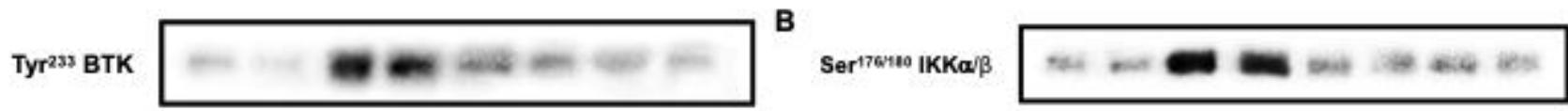

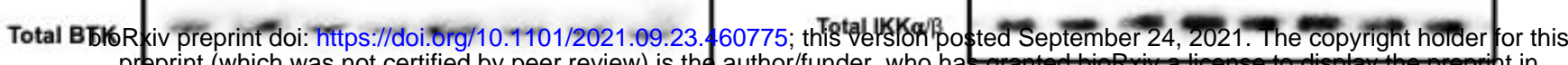
preprint (which was notcertified by peer review) is the author/funder, who has grantect bionxiv a ticentse to cisplay the prepritht in
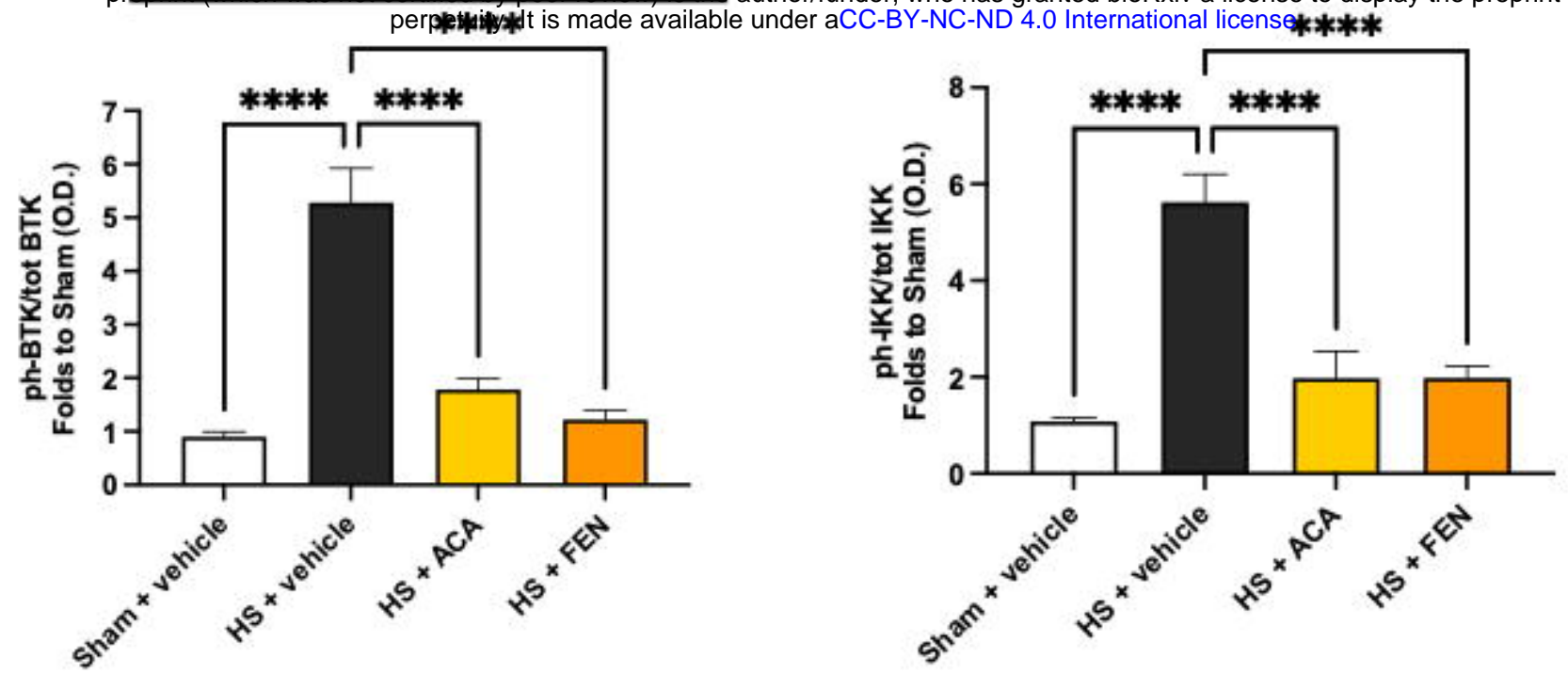

C
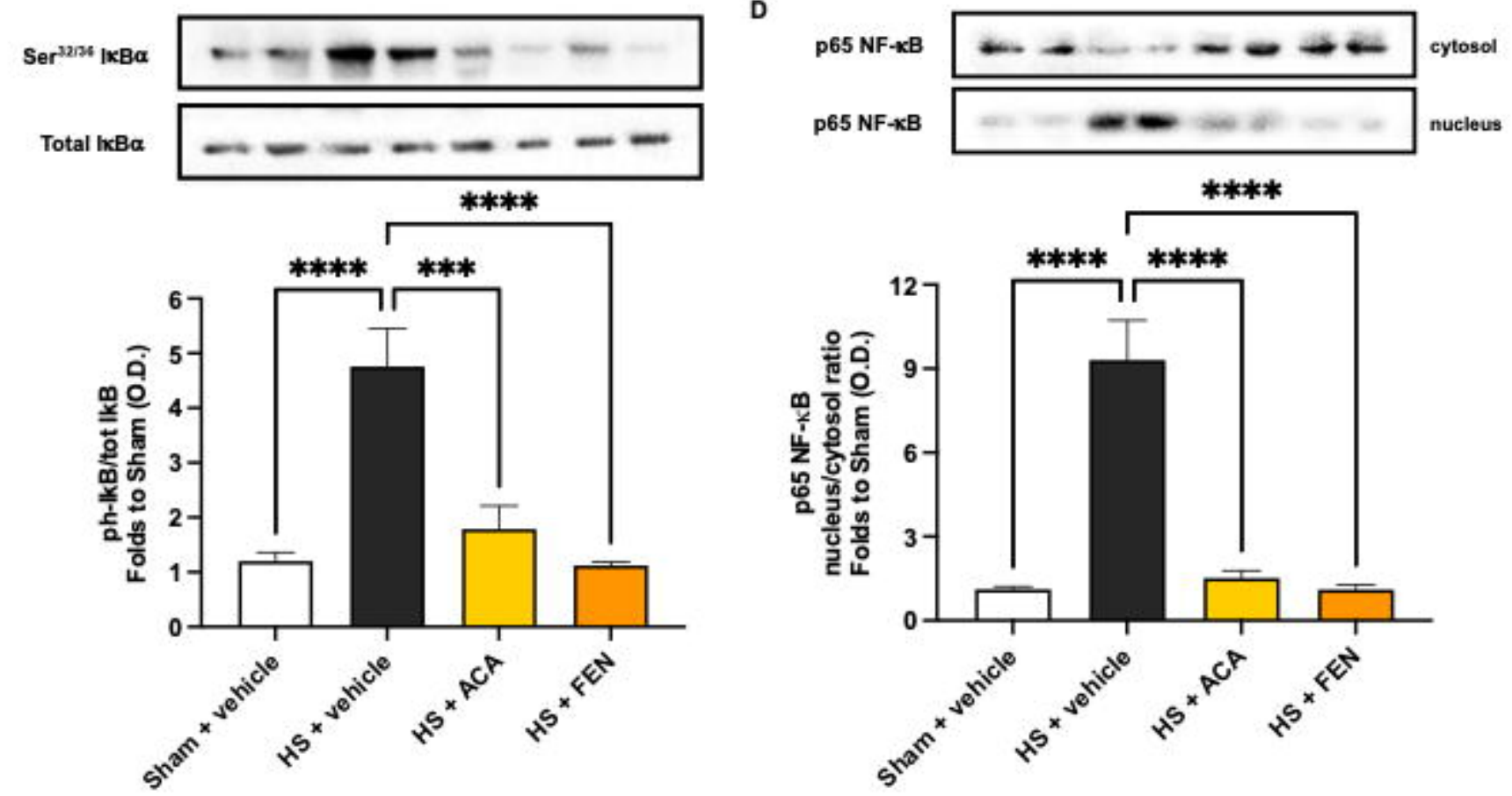

$\mathbf{E}$
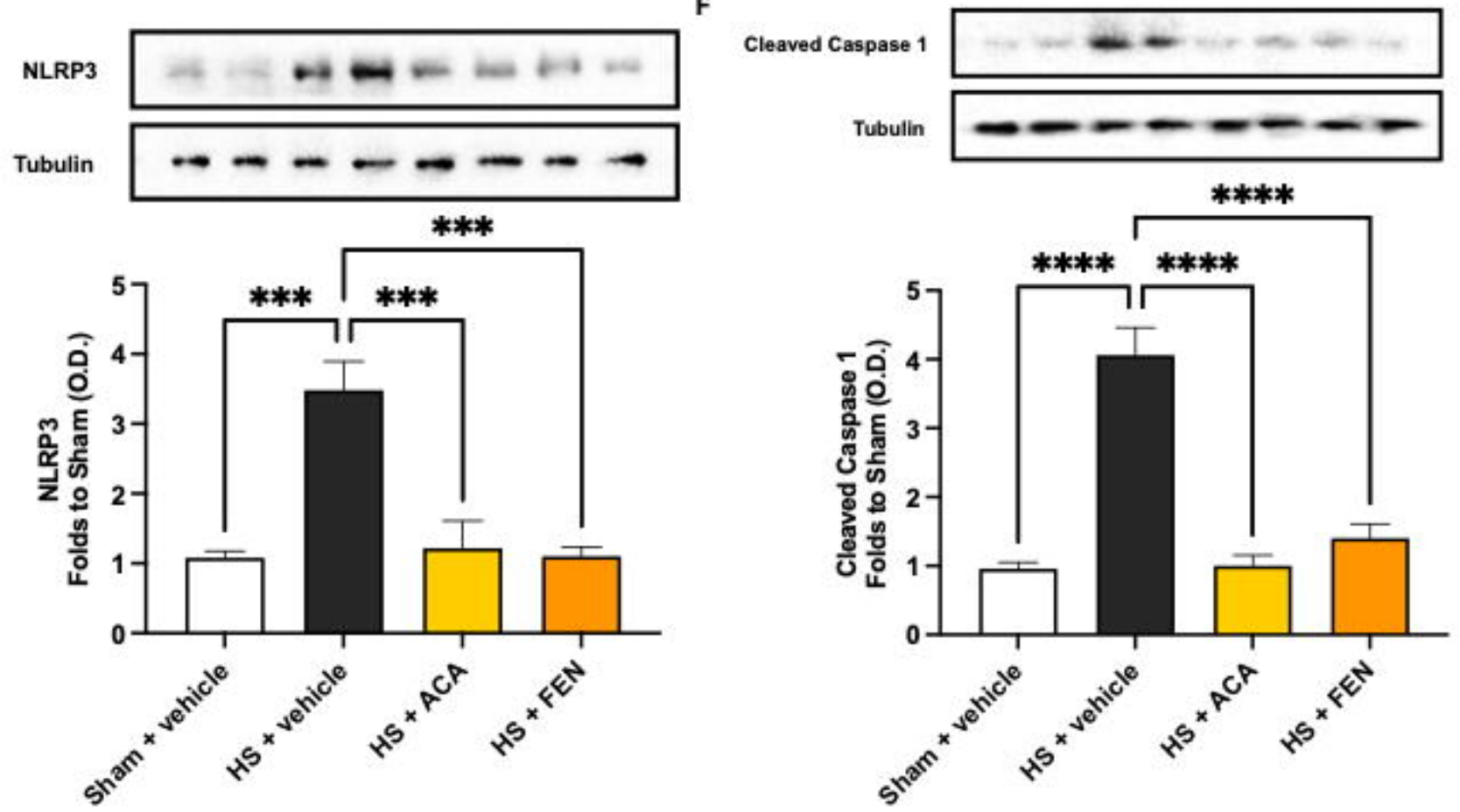
A

preprint (which was not certified by peer review) is the anthor/funder, who has granted bioRxiv a license to display the preprint in
perpetuity. It is made available
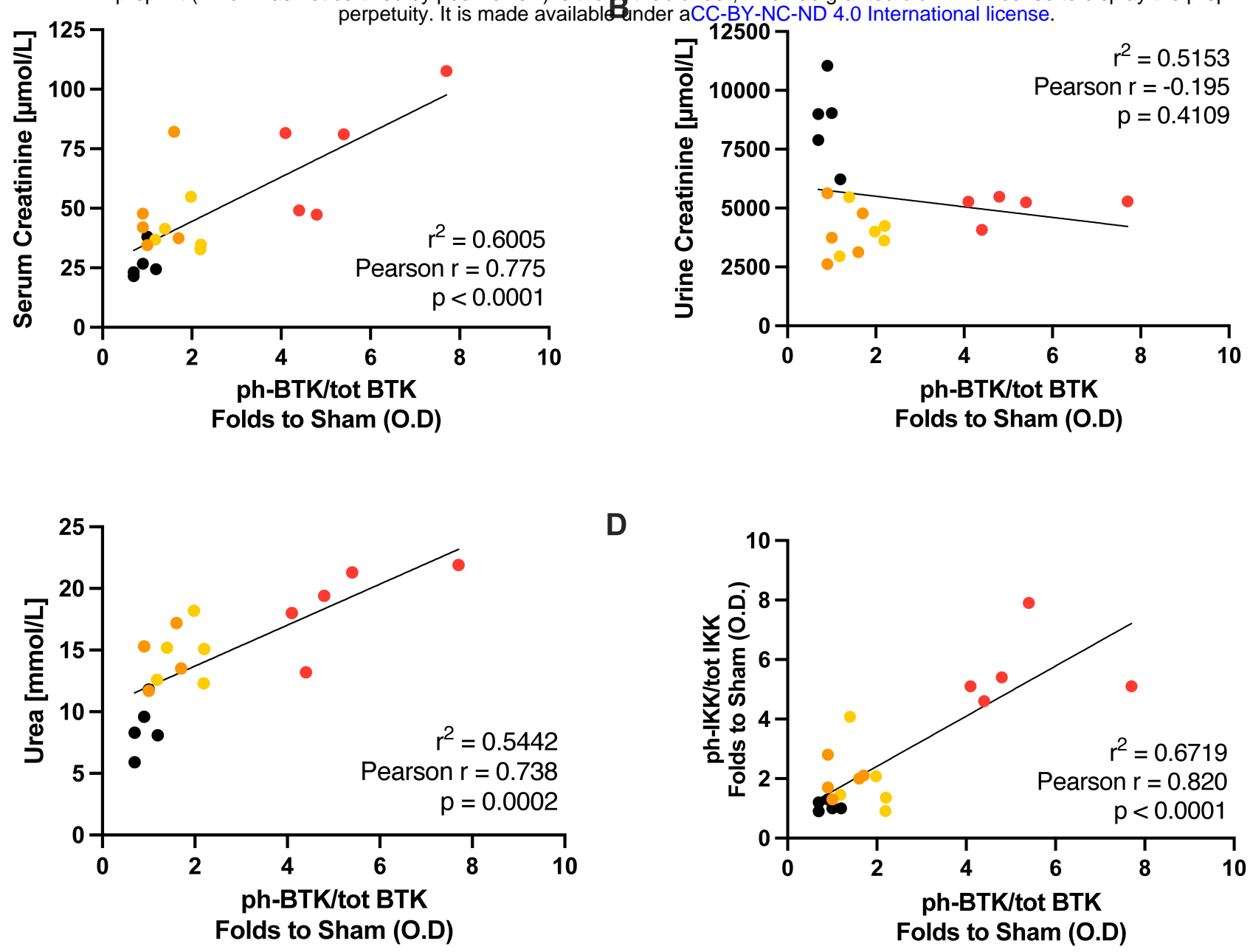

$\mathbf{E}$

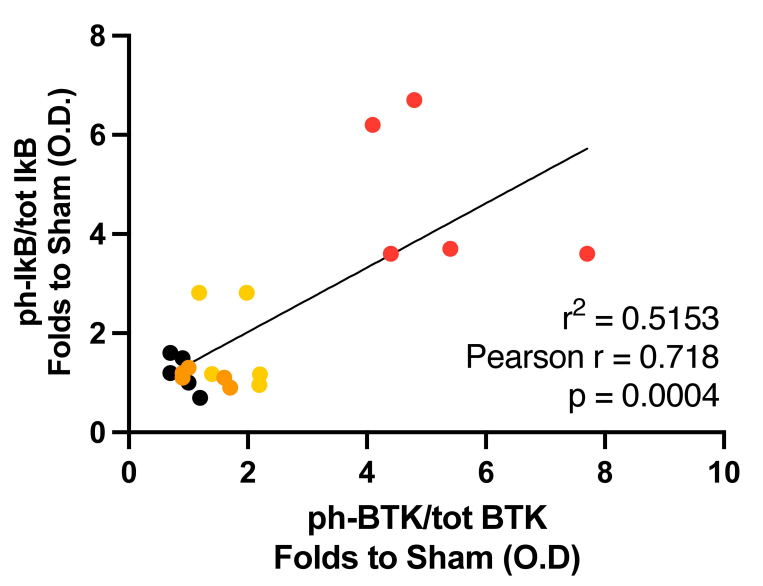

G

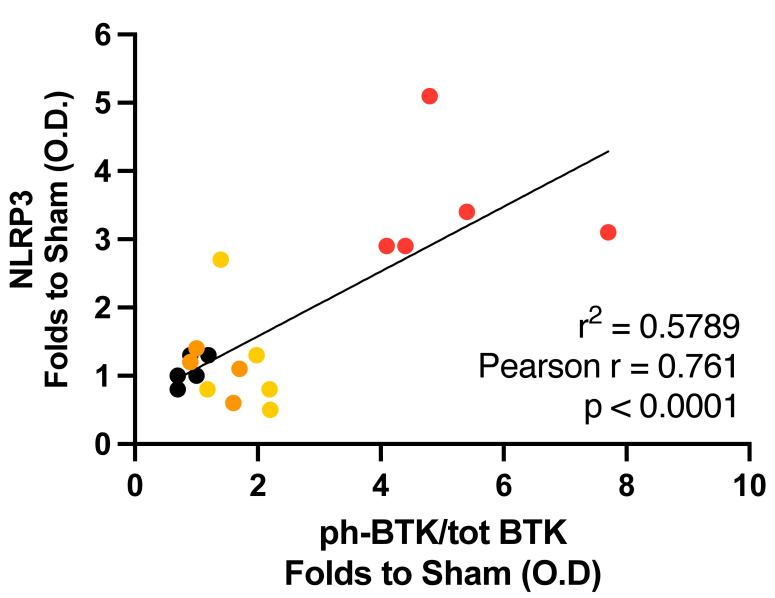

D

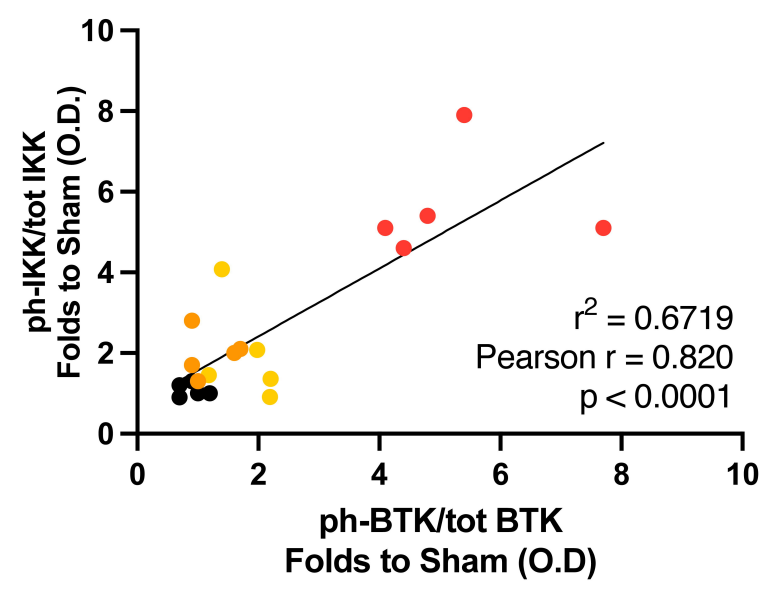

F

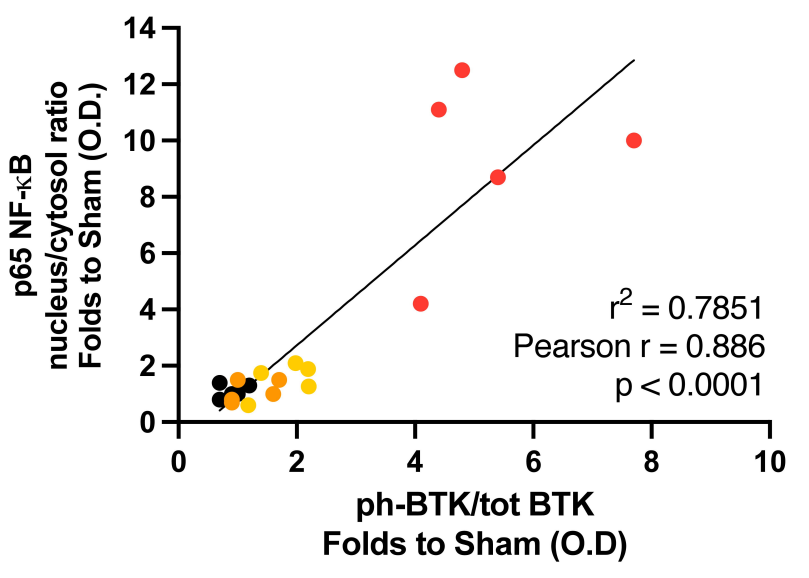

H

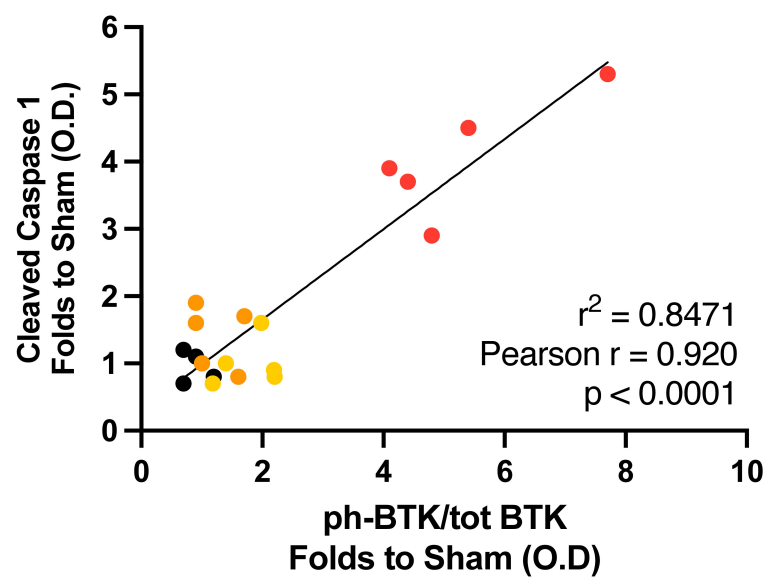


A

B

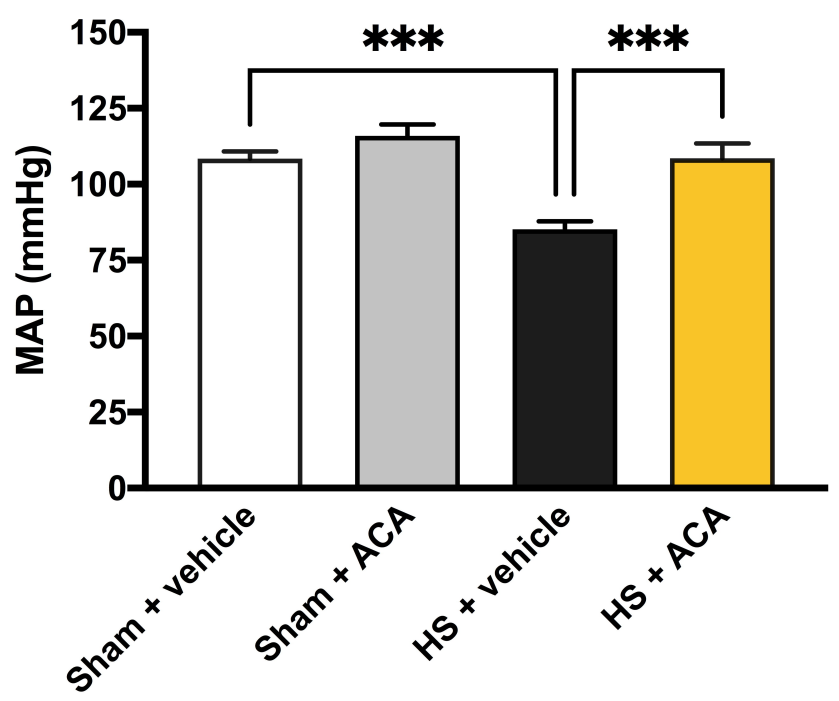

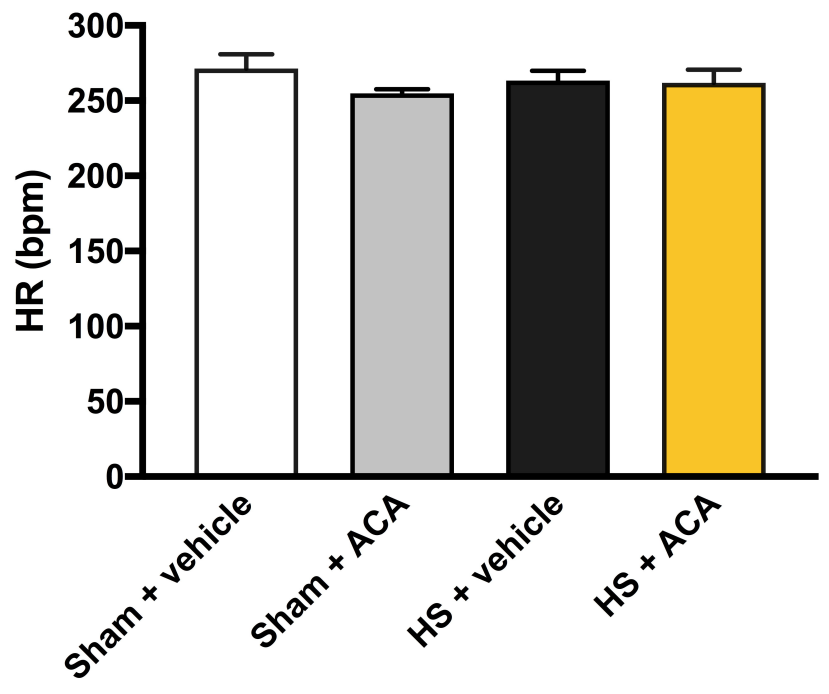


